Reprod. Nutr. Dévelop., 1983, 23 (3), 453-491.

\title{
La gonadogenèse des Poissons
}

\author{
J. BRUSLÉ, Solange BRUSLÉ
}

Laboratoire de Biologie marine, Université de Perpignan, avenue de Villeneuve, 66025 Perpignan Cedex, France.

Summary. Gonadogenesis in fish.

This paper is a general review of gonadogenesis in fish. Data in the literature deal with gonadal development and sexual differentiation and their variability in different species in correlation with the effects of environmental factors and steroid activity. The practical interest of gonadogenesis in fish culture has been discussed.

\section{Sommaire.}

Introduction.

I. - Origine des constitutants gonadiques et morphogenèse des ébauches génitales.

II. - Modalités de la différenciation gonadique.

III. - Variabilité de la différenciation gonadique dans le temps et dans l'espace.

IV. - Rôle des facteurs de l'environnement et des stéroïdes sexuels.

V. - Intérêt pratique : contrôle du sexe appliqué à l'élevage des Poissons.

Discussion générale et conclusion.

\section{Introduction.}

La sexualité des Poissons se caractérise par la grande variété de ses modalités d'expression (gonochorisme primaire ou secondaire, hermaphrodisme, intersexualité) ainsi que par la labilité de la différenciation sexuelle et de l'activité fonctionnelle (D'Ancona, 1950 ; Bertin, 1958 ; Atz, 1964 ; Vivien, 1964 ; Yamamoto, 1969 ; Harrington, 1974).

La détermination du sexe est d'ordre génotypique, liée à la fécondation (syngamique), ainsi que l'ont montré les recherches poursuivies sur Xiphophorus maculatus (Gordon, 1946, 1951 et 1952 ; Gordon et Aronowitz, 1951 ; Chavin et Gordon, 1951 ; Kallman, 1970 ; Kallman et Schreibman, 1973), Rivulus marmoratus (Harrington, 1967) et surtout sur Oryzias latipes (Aida, 1921 ; Yamamoto, 
1958, 1959, 1962, 1963 et 1968 ; Yamamoto et Matsuda, 1963 ; Yamamoto et al., 1968). Les principales revues consacrées à la détermination chromosomique du sexe des Téléostéens sont dues à Harrington (1967 et 1974), Mittwoch (1973), Ohno (1979) et Purdom (1979).

Le sexe est d'expression phénotypique, ce qui est " déterminé " à la fécondation étant la combinaison des gènes sexuels mais pas le sexe lui-même. Cette différenciation sexuelle, phénotypique, est généralement conforme au génotype mais elle peut s'en écarter (intersexualité, inversion sexuelle: Reinboth, 1970, 1975 et 1980) en raison de l'influence de facteurs épigénétiques (facteurs de I'environnement tels que la température : Harrington, 1967, 1974 et 1975, alimentation et densité de population: Passakas et Tesch, 1980, facteurs sociaux : Reinboth, 1980) ou à la suite d'interventions expérimentales agissant au niveau des inducteurs sexuels (hormones stéroïdes: Donaldson et Hunter, 1982).

De nombreuses recherches ont été engagées sur les plans histologique et cytologique, visant à décrire les étapes de la gonadogenèse chez les Cyclostomes, les Elasmobrariches et surtout les Téléostéens. Les études descriptives de morphogenèse, à l'échelle photonique, ont été complétées par des recherches expérimentales qui ont été poursuivies essentiellement sur des espèces d'eau douce : Salmonidés, Cichlidés et surtout Cyprinodontiformes (voir tabl. 1). Ces recherches concernent surtout des interventions endocrinologiques (utilisation de stérödes sexuels : Chieffi, 1959 ; Yamamoto, 1959 ; Dzwillo, 1966 ; Takahashi et Takano, 1971 ; Onitake, 1972 ; Nakamura et Takahashi, 1973; Jalabert et al., 1974b ; Upadhyay, 1977 ; Tayamen et Shelton, 1978 ; Jensen et Shelton, 1979 ; Nakamura, 1981; Shelton et al., 1981; Yoshikawa et Oguri, 1981 ; van den Hurk et al., 1982 - contrôles par hypophysectomie : Ashby, 1957, 1964 ou par des inhibiteurs tels que le méthallibure ou l'acétate de cyprotérone : Hopkins et al., 1979; Hamaguchi, 1979). L'influence des facteurs de l'environnement, en particulier de la température, a été testée (Padoa, 1939 ; Ashby, 1964 ; Harrington, 1967, 1974 et 1975 ; Jalabert et al. 1974a ; Kuhlman, 1975; Magomedov et al., 1979). Notons que les analyses cytologiques à l'échelle ultrastructurale ont été relativement rares (Satoh et Egami, 1973 ; Satoh, 1974 ; Upadhyay, 1977 ; Bruslé, 1982 ; van der Hurk et al., 1982).

Le tableau 1 présente toutes les espèces étudiées et les types d'observation, descriptives ou expérimentales, réalisées.

Rappelons enfin que plusieurs articles généraux ont été consacrés à la différenciation du sexe des Poissons et Cyclostomes (D'Ancona, 1956; Atz, 1964 ; Hardisty, 1965, 1967 et 1970 ; Yamamoto, 1969 ; Persov, 1975 ; Lepori, 1980 ; Billard et al., 1982), mais qu'aucune mise au point complète ne concerne la gonadogenèse. Une meilleure connaissance de celle-ci présente un intérêt non seulement fondamental (différenciation cellulaire, inducteurs sexuels, phylogenèse) mais aussi appliqué (contrôle du sexe en élevage; Yamazaki, 1976 ; Donaldson et Hunter, 1982 et en particulier production de populations monosexuées ou stériles: Chevassus et al., 1979a, b ; Stanley, 1981).

Ce travail se propose de présenter un tableau aussi complet et synthétique que possible de l'état actuel des connaissances sur les problèmes de la gonadogenèse des Poissons. 


\section{TABLEAU I}

Gonadogenèse chez les Cyclostomes et les Poissons

par espèce et par auteur

(classification d'après Jordan, 1963)

- Cyclostomes

Entosphenus wilderi : Okkelberg, 1921.

Lampetra fluviatilis : Hardisty, 1967, 1970.

Lampetra planeri : Busson-Mabillot, 1965; Hardisty, 1965, 1967, 1970 ; Hardisty et Cosh, 1966. Petromyzon marinus : Hardisty, 1967, 1969 ; Hardisty et Cosh, 1966.

- Poissons

- Elasmobranches

- Scyliorhinidés : Scyliorhinus canicula : Chieffi, 1950, 1955, 1959 ; Collenot, 1969; Thiebold, 1964.

- Torpedinidés : Torpedo marmorata: Chieffi, 1951. Torpedo ocellata : Thiebold, 1964.

- Chondrostéens

- Acipenséridés : Acipenser baeri : Persov, 1972.

Acipenser guldenstadti : Persov, 1972 ; Mailyan et Alekperov, 1976. Acipenser stellatus: Trusov, 1971.

- Holostéens

- Amiidés : Amia calva : D'Ancona, 1955.

- Dipneustes

Polypterus senegalensis : De Smet, 1975.

Polypterus sp.: De Smet, 1970.

- Téléostéens

- Anabantidés :

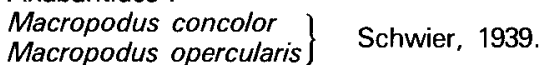

- Anguillidés : Anguilla anguilla : Grassi, 1919 ; Rodolico, 1933 ; Fidora, 1951 ; D'Ancona, 1924, 1943, 1953 ; Kuhlman, 1975 ; Dolan et Power, 1976 ; Brylinska et al., 1978 ; Colombo et Rossi, 1978 ; Passakas et Tesch, 1980 ; Bieniarz et al., 1981.

- Athérinidés : Atherina mochon : Arru, 1968.

- Batrachoididés : Opsanus tau: Odum, 1936.

- Centrarchidés : Micropterus salmoides : Johnston, 1951.

- Channidés : Channa punctatus : Belsare, 1966.

- Cichlidés : Cichlasoma biocellatum: Hackmann, 1974. Hemihaplochromis multicolor: Muller, 1969; Hackmann, 1974 ; Hackmann et Reinboth, 1974. Tilapia (= Sarotherodon) aurea: Guerrero, 1975; Avtalion et Mires, 1976; Jensen et Shelton, 1979 ; Dutta, 1979 (cité par Shelton et al., 1981) ; Hopkins et al., 1979 ; Shelton et al., 1981.

Tilapia hornorum : Chen, 1969.

Tilapia macrochir : Jalabert et al., 1971, 1974b. 
Tilapia mossambica : Clemens et Insiee, 1968; Nakamura et Takahashi, 1973 ; Hackmann, 1974 ; Nakamura, 1975 ; Jensen et Shelton, 1979 ; Nakamura, 1981.

Tilapia nilotica: Jalabert et al., 1974b ; Tayamen et Shelton, 1978.

Tilapia zillii : Yoshikawa et Oguri, 1978a, b.

- Clariidés :

Clarias batrachus : Belsare, 1974.

- Clupéidés :

Sardina pilchardus : Pinto et Andreu, 1956.

- Cyprinidés :

Brachydanio rerio: Takahashi, 1977.

Carassius auratus: Natali et Natali, 1947 ; Yamamoto et Kajishima, 1968 ; Takahashi et Takano, 1971 ; Kanobdee, 1975.

Ctenopharyngodon idella: Shelton, 1982.

Cyprinus carpio: Nedelea et Steopoe, 1970; Davies et Takashima, 1980 ; Ryazantseva et Sakun, 1980.

Hypophthalmichtys molitrix: Yemel'Yanova, 1976.

Idus idus : Cala, 1970, 1976.

Vimba : Sakun, 1959 ; Persov, 1972.

- Cyprinodontidés :

Oryzias latipes: Yamamoto, 1953, 1959, 1962, 1963, 1968 ; Yamamoto et al., 1968 ; Yamamoto et Matsuda, 1963; Gamo, 1961; Hishida, 1962, 1964; Tuzuki et al., 1966 ; Hishida et Kawamoto, 1970 ; Onitake, 1972 ; Satoh et Egami, 1972, 1973 ; Hogan, 1973 ; Hosakawa, 1973 ; Quirk et Hamilton, 1973; Satoh, 1973, 1974 ; Hamaguchi, 1979; Yoshikawa et Oguri, 1979, 1981.

Rivulus marmoratus : Harrington, 1967, 1974, 1975.

- Gastérostéidés :

Gasterosteus aculeatus : Swarup, 1958 ; Shimizu et Takahashi, 1980.

- Labridés :

Crenilabrus quinquemaculatus : Arru, 1966.

- Mugilidés :

Mugil cephalus : Stenger, 1959.

Liza aurata : Bruslé et Bruslé, 1978b ; Bruslé, 1980, 1982.

- Percidés :

Perca fluviatilis: Chevey, 1925 ; Lissia-Frau, 1968 ; Mezhnin, 1978 ; Zelenkov, 1981.

- Poécilidés :

Gambusia sp. : Chambolle, 1973.

Gambusia holbrookii : Lepori, 1941, 1950 ; Pala, 1968, 1970.

Mollienisia : van den Hurk, 1974.

Poecilia reticulata $(=$ Lebistes reticulatus): Goodrich et al., 1934 ; Dildine, 1936 ; Berkowitz, 1941; Mohsen, 1958 ; Anteunis, 1959; Miyamori, 1964; Takano, 1965; Dzwillo, 1966 ; Bodemer, 1971; Billard, 1973 ; Takahashi et Iwasaki, 1973 ; Takahashi, 1974, 1975a et b.

Xiphophorus helleri : Regnier, 1938 ; Vallowe, 1957 ; Mohsen, 1958.

Xiphophorus maculatus : Gordon et Aronowitz, 1951; Gordon, 1952 ; Chavin et Gordon, 1951.

- Salmonidés :

Oncorhynchus gorbusha: Persov, 1972 ; Funck et al., 1973.

Oncorhynchus keta: Mahon et Hoar, 1956 ; Robertson, 1953 ; Magomedov et al., 1979.

Oncorhynchus kisutch : Persov, 1975 ; Goetz et al., 1979 ; Yu et al., 1979.

Oncorhynchus masou: Nakamura et al., 1974.

Salmo gairdneri : Mrsic, 1923, 1930 ; Padoa, 1939 ; Jalabert et al., 1974a ; Simpson, 1975-76 ;

Vlad, 1976 ; Lebrun, 1977; Upadhyay, 1977; van den Hurk et al., 1979, 1980, 1982;

Secombes et al., 1982 ; Takashima et al., 1980 ; Johnstone et al., 1979a ; Okada et al., 1979 ; van den Hurk et Slof, 1981 ; van den Hurk et Lambert, 1982.

Salmo salar : Felix, 1906 ; Persov, 1975 ; Laird et al., 1978.

Salmo trutta : Ashby, 1957, 1959, 1964.

Salvelinus fontinalis : Yamazaki, 1976 ; Johnstone et al., 1979b.

Salvelinus namaycush: Wenstrom, 1975 (cité par Donaldson et Hunter, 1982). 
- Serranidés :

Dicentrarchus labrax : Chevey, 1925 ; Roblin, 1980 ; Roblin et Bruslé, 1983.

Serranus hepatus: Bruslé, 1982, 1983.

- Sparidés :

Boops salpa : D'Ancona, 1949a ; Lissia-Frau et Casu, 1968; Malo-Michele, 1977.

Boops boops, Diplodus vulgaris, Diplodus sargus, Diplodus annularis, Lithognathus mormyrus, Oblada melanura, Puntazzo puntazzo, Sparus auratus : D'Ancona, 1949a, b ; Lissia-Frau et Casu, 1968 ; Lepori, 1980.

\section{I. - Origine des constituants gonadiques et morphogenèse des ébauches génitales.}

Les principales étapes de la différenciation phénotypique du sexe sont, d'après Persov (1972), les suivantes :

1) Période indifférenciée.

- Stade prégonadique :

1) ségrégation des cellules germinales primordiales (CGP) ;

2) migration des CGP ;

3) concentration des CGP dans la région de formation des futures gonades ( = primordium gonadique $)$.

- Formation des gonades:

4) mise en place des crêtes génitales ;

5) migration des CGP vers les crêtes génitales.

2) Différenciation gonadique.

a) Anatomique : changements structuraux, édification ovarienne ou testiculaire ;

b) Cytologique : différenciation des ovogonies et ovocytes ou des spermatogonies et spermatocytes.

Comme l'a fait remarquer D'Ancona (1956), la gonade n'est pas l'organe qui donne naissance aux éléments germinaux mais seulement l'organe dans lequel, provenant $d^{\prime}$ autres territoires, ces éléments se multiplient et se différencient.

\section{A) Origine et caractéristiques des cellules germinales primordiales (CGP).}

1) Ségrégation. - Les gonocytes primordiaux ou cellules germinales primordiales (CGP) prennent leur origine au cours de l'embryogenèse précoce dans I'endomésoderme extraembryonnaire. Leur ségrégation des blastomères vitellins s'effectue très tôt, soit dès le stade blastula (Oncorhynchus : Mahon et Hoar, 1956), soit plus souvent au cours de la gastrulation (Gambusia: Pala, 1968 et 1970 ; Cyprinus : Nedelea et Steopoe, 1970 ; Oryzias : 3 jours après la fécondation, Gamo, 1961 ; Satoh et Egami, 1973). Elle se produit parfois à la fin de la gastrulation (Perca: Mezhnin, 1978) ou plus tard, à l'éclosion (Clarias : Belsare, 1974). Le site même de ségrégation germinale a donné lieu à des interprétations différentes et contradictoires (Johnston, 1951; Gamo, 1961). La plupart des auteurs considèrent que le lieu d'apparition des CGP est l'endoderme présomptif 
(De Smet, 1970, chez Polypterus ; Bodemer, 1971, chez Poecilia ; Onitake, 1972 et Hogan, 1973, chez Oryzias ; Hahn, 1927, chez Cottus) et en particulier le vitellus sous-intestinal, dans la région postérieure du sac vitellin (périblaste de la région caudale: Mezhnin, 1978). Toutefois, d'autres auteurs (Pala, 1970, chez Gambusia ; Nedelea et Steopoe, 1970, chez Cyprinus) attribuent cette origine au mésoderme présomptif et certains (Gamo, 1961, chez Oryzias ; Muller, 1969, chez Hemihaplochromis) considèrent que les CGP se différencient à la fois dans l'endoderme et dans le mésoderme présomptifs. De plus, des similitudes relatives aux modalités de la ségrégation des CGP, aussi bien chez les Poissons que chez les Cyclostomes (Hardisty, 1967), ont été observées, les différences intraspécifi. ques et la variabilité interspécifique étant discrètes.

2) Migration. - Il est généralement admis que les CGP se déplacent, par amoeboïdisme, depuis le vitellus sous-intestinal jusqu'au mésentère dorsal via le mésoderme ventral et via le mésoderme splanchnique (Johnston, 1951 ; Gamo, 1961 ; Mezhnin, 1978). Ces gonocytes présentent d'ailleurs des pseudopodes caractéristiques (Nedelea et Steopoe, 1970).

3) Concentration (dans la région du futur primordium gonadique). - Les CGP se retrouvent, à l'issue de leur migration, groupées à la racine du mésentère dorsal (Nakamura et Takahashi, 1973 ; Yoshikawa et Oguri, 1978a, b, chez Tilapia ; Pala, 1968, chez Gambusia ; Gamo, 1961, chez Oryzias) ou à son voisinage (Ryazantseva et Sakun, 1980 chez Cyprinus ; Roblin et Bruslé, 1983, chez Dicentrarchus).

4) Cytologie. - La plupart des études cytologiques de CGP ont été effectuées au microscope photonique et les seules observations ultrastructurales sont dues à Hogan (1973), Satoh et Egami (1973), Satoh (1974), Kanobdee (1975), Bruslé et Bruslé (1978b), Bruslé (1980, 1982). Les critères de taille cellulaire sont les plus utilisés (tabl. 2), les valeurs des diamètres cellulaires variant très sensiblement d'une espèce à l'autre. Le rapport nucléoplasmique $(0,4 \pm 0,1$ : Bruslé, 1982) et I'organisation structurale, décrite notamment par Bruslé (1980, 1982), et caractérisée par des contours cellulaires et nucléaires irréguliers, une densité électronique élevée liée à une grande richesse en ribosomes, un noyau volumineux, une pauvreté générale en organites cytoplasmiques et la présence de matériel dit nuage et ciment, confèrent à ces CGP une originalité et une identité propre bien distincte de celle des gonies (spermatogonies et ovogonies) qui seront issues d'elles.

5) Nombre. - Des revues générales portant sur le nombre des CGP ont été publiées par Johnston (1951), Hardisty (1965 et 1967) et Persov (1972). Les auteurs ont insisté sur l'existence de différences spécifiques, (Persov, 1972) ainsi que sur les grandes variations individuelles (Johnston, 1951). Le nombre des CGP varie de 20 à 100 chez $70 \%$ des Vertébrés étudiés (Hardisty, 1967) et se situe autour de 47 chez la Truite (Lebrun, 1977). Il est toutefois relativement uniforme et contraste avec les grandes divergences dans les taux de fécondité ; il ne présente d'ailleurs aucune relation directe évidente avec le nombre définitif de cellules sexuelles (Hardisty et Cosh, 1966). Aucune différence numérique liée au 
sexe ne serait décelable jusqu'au primordium gonadique chez Oryzias (à l'éclosion, les $\delta$ possèdent 72 CGP et les $\subsetneq 75$ d'après Quirk et Hamilton, 1973). Toutefois, d'autres auteurs (Wolf, 1931, chez Xiphophorus) admettent que le nombre des CGP est nettement supérieur chez les femelles à celui des mâles. Une augmentation du nombre des CGP impliquant des divisions mitotiques au cours de la migration a été observée dans certains cas (Muller, 1969 ; Nedelea et Steopoe, 1970 ; Belsare, 1974 ; Mezhnin, 1978) mais elle a été mise en doute par Gamo (1961) et Hardisty (1965) qui considèrent que les divisions cellulaires ne se produisent pas depuis la ségrégation jusqu'au primordium gonadique. Elles ne se manifestent qu'au $8^{\mathbf{e}}$ jour chez Brachydanio (Takahashi, 1977) et Gasterosteus (Shimizu et Takahashi, 1980) entre le $20^{\mathrm{e}}$ et le $40^{\mathrm{e}}$ jour chez Cyprinus (Ryazantseva et Sakun, 1980). Chez Oryzias (Hamaguchi, 1979), la prolifération se répartit en deux vagues successives : avant l'éclosion dans le primordium puis 15 jours après l'éclosion.

\section{TABLEAU 2}

Taille cellulaire des CGP au cours de l'ontogenèse précoce des gonades

\begin{tabular}{|c|c|c|}
\hline Espèces & $\begin{array}{l}\text { Diamètre cellulaire } \\
\qquad(\mu \mathrm{m})\end{array}$ & Auteur(s) \\
\hline $\begin{array}{l}\text { Centrarchidés } \\
\quad \text { Micropterus salmoides }\end{array}$ & $11-13$ & Johnston, 1951 \\
\hline $\begin{array}{l}\text { Channidés } \\
\text { Channa punctatus }\end{array}$ & $9-10$ & Belsare, 1966 \\
\hline $\begin{array}{l}\text { Cichlidés } \\
\text { Tilapia mossambica } \\
\text { Tilapia zillii }\end{array}$ & $\begin{array}{l}13-16 \\
13-16\end{array}$ & $\begin{array}{l}\text { Nakamura et Takahashi, } 1973 \\
\text { Yoshikawa et Oguri, 1978a }\end{array}$ \\
\hline $\begin{array}{l}\text { Clariidés } \\
\text { Clarias batrachus }\end{array}$ & $14-16$ & Belsare, 1974 \\
\hline $\begin{array}{l}\text { Cyprinidés } \\
\text { Carassius auratus } \\
\text { Cyprinus carpio }\end{array}$ & $\begin{array}{c}9-17 \\
10\end{array}$ & $\begin{array}{l}\text { Kanobdee, } 1975 \\
\text { Davies et Takashima, } 1980\end{array}$ \\
\hline $\begin{array}{l}\text { Cyprinodontidés } \\
\text { Oryzias latipes }\end{array}$ & $\begin{array}{l}15-20 \\
15-30\end{array}$ & $\begin{array}{l}\text { Satoh et Egami, } 1973\left(^{*}\right) \\
\text { Hogan, } 1973 \text {; Satoh, } 1974\left(^{*}\right)\end{array}$ \\
\hline $\begin{array}{l}\text { Dipneustes } \\
\quad \text { Polypterus senegalensis }\end{array}$ & $20-40$ & De Smet, 1975 \\
\hline $\begin{array}{l}\text { Mugilidés } \\
\text { Liza aurata } \\
\text { Mugil cepha/us }\end{array}$ & $\begin{aligned} 12,1 \pm 1,8 & \times 9,0 \pm 1,7 \\
9,58 \pm 1,2 & \times 6,03 \pm 1,17\end{aligned}$ & $\begin{array}{l}\text { Bruslé, } 1982\left(^{*}\right) \\
\text { Bruslé, } 1980\left({ }^{*}\right) \text { et } 1982\left(^{*}\right)\end{array}$ \\
\hline $\begin{array}{l}\text { Poecilidés } \\
\text { Poecilia reticulata }\end{array}$ & $10-14$ à 20 & Billard, 1973 \\
\hline $\begin{array}{l}\text { Salmonidés } \\
\text { Oncorhynchus keta } \\
\text { Salmo gairdneri }\end{array}$ & $\begin{array}{c}21 \\
12-22 \\
17-22\end{array}$ & $\begin{array}{l}\text { Magomedov et al., } 1979 \\
\text { Takashima et al., } 1980 \\
\text { van den Hurk et Slof, } 1981\end{array}$ \\
\hline $\begin{array}{l}\text { Serranidés } \\
\text { Serranus cabrilla } \\
\text { Serranus hepatus }\end{array}$ & $\begin{array}{l}10,8 \pm 1,9 \times 6,5 \pm 1,5 \\
12,99 \pm 2,57 \times 8,47 \pm 1,4\end{array}$ & $\begin{array}{l}\text { Bruslé, } 1982\left(^{*}\right) \\
\text { Bruslé, } 1982\left({ }^{*}\right), 1983\left({ }^{*}\right)\end{array}$ \\
\hline
\end{tabular}

(*) A l'échelle ultrastructurale. 


\section{B) Origine des constituants somatiques.}

\section{1) Edification du primordium gonadique.}

La gonade des Vertébrés présente classiquement une organisation bisexuelle caractéristique, liée à la dualité initiale, d'origine embryologique, de son stroma somatique constitutif. La bipotentialité sexuelle des gonades primitives reposerait, selon une conception ancienne applicable aux Amphibiens (Witschi, 1934 et 1942) et aux Mammifères (revue de Ohno, 1979), sur I'existence d'un double substrat somatique, le cortex et la médulla différant par leur origine et dont les potentialités seraient respectivement femelle et mâle. La différenciation serait alors le résultat de l'activité antagoniste des constituants du couple cortico-médullaire et résulterait de la production d'inducteurs hypothétiques de type « corticine » et " medullarine » (Witschi, 1950, 1957), " gynogénine » et " androgénine " (D'Ancona, 1950), « gynotermones » et " androtermones " (Yamamoto, 1962). Ce schéma, admis chez les Amphibiens (Witschi, 1950), s'appliquerait aux Elasmobranches (Chieffi, 1949 à 1959), mais ne concernerait ni les Cyclostomes ni les Téléostéens chez lesquels, en l'absence d'un blastème rénal mésonéphrétique, seul le cortex dérivant de la paroi péritonéale participerait à l'édification de l'ébauche génitale (D'Ancona, 1943 à 1955).

Ces notions, longtemps jugées classiques, ont été remises en cause tant chez les Mammifères (Gropp et Ohno, 1966 ; Zamboni et al., 1979 ; Byskov, 1978) que chez les Poissons (Harrington, 1974 et 1975). Chez les Téléostéens, ce dernier auteur a en effet jugé le stroma du hile ( médial ramus ») équivalant à la médulla gonadique de Witschi. Une autre conception « dualiste » a été présentée par Lepori (1980), selon laquelle le primordium, simple et d'origine exclusivement péritonéale (épithélium coelomique du mésoblaste latéral), serait formé de deux territoires cellulaires distincts à destinées sexuelles différentes (zone proche du mésogonium à potentialité femelle et zone distale à potentialité testiculaire).

Le primordium gonadique est constitué de plusieurs catégories d'éléments somatiques: cellules épithéliales, fibroblastes, fibres collagènes (Roblin et Bruslé, 1983). Dans l'ovaire présomptif de la Truite, à l'échelle ultrastructurale, Upadhyay (1977) a montré I'existence d'une zone superficielle faite de cellules épithéliales entourant les cellules germinales et recouverte par un mésothélium de surface, nettement séparée par une lame basale du stroma conjonctif sousjacent. L'origine et le devenir de ces divers constituants ont été discutés par cet auteur mais de nouvelles recherches, à des stades plus précoces et concernant également le testicule présomptif, s'avèrent encore nécessaires.

\section{2) Morphogenèse gonadique.}

a) La crête génitale. - L'édification de la crête génitale des Téléostéens suppose la différenciation et l'organisation des cellules somatiques issues de la paroi somatopleurale de la cavité péritonéale ainsi que leur colonisation par les CGP. Suspendue, au niveau de son hile à la paroi péritonéale dorsale ou dorsolatérale de la cavité coelomique par le mésogonium (Cala, 1970; Nakamura et 
Takahashi, 1973 ; Lepori, 1980), cette crête génitale est constituée par un cordon continu de cellules somatiques (mésothéliales, fibroblastiques...) dans lequel des CGP sont distribuées de façon discontinue (Johnston, 1951; Swarup, 1958 ; Belsare, 1974 ; Roblin et Bruslé, 1983). Elles peuvent être plus concentrées en direction crâniale (Lissia-Frau, 1968, chez Perca ; Davies et Takashima, 1980; Ryazantseva et Sakun, 1980, chez Cyprinus), en direction caudale (Odum, 1936 chez Opsanus; Mezhnin, 1978 chez Perca; Bruslé, 1982 chez Liza ; Roblin et Bruslé, 1983 chez Dicentrarchus) ou en position moyenne (Takashima et al., 1980 chez Salmo). Leur distribution peut même préfigurer leur évolution ultérieure. Ainsi, chez Salmo gairdneri, la concentration des gonocytes dans un renflement antérieur caractérise une future différenciation ovarienne alors que leur répartition sur toute la longueur de l'ébauche est le propre des testicules présomptifs (Lebrun, 1977).

b) La gonade indifférenciée. - La prolifération des cellules germinales, bien que rarement observée (Magomedov et al., 1979). et le développement parallèle du stroma conjonctif conduisent à la réalisation d'une ébauche gonadique bien individualisée au sein de laquelle se situeront les processus morphologiques, cytologiques et physiologiques traduisant la sexualisation. Au cours de cette période d'indifférenciation, les cellules germinales primordiales, qui constituent les cellules-souches et sont considérées comme bipotentes (Hogan, 1973 ; Satoh et Egami, 1973; Bruslé et Bruslé, 1978b ; Bruslé, 1980, 1982) sont toujours entourées par des cellules somatiques qui leur sont annexées (Kanobdee, 1975 ; Upadhyay, 1977 ; Bruslé, 1982). Quelles que soient leur dénomination (« neighbouring somatic cells ": Satoh, 1974 ; " epitheloid cells »: Upadhyay, 1977 ; " peritoneal cells »: Hogan, 1978) et leur origine, ces cellules sont elles-mêmes jugées bipotentes (évolution sertolienne ou préfolliculeuse). L'association structurale intime du " couple CGP-cellule somatique » est susceptible de jouer un rôle important dans le maintien du caractère indifférencié grâce à un microenvironnement spécifique créé autour de la cellule sexuelle (Bruslé, 1982).

c) L'ovotestis. - L'ontogenèse des gonades hermaphrodites a fait l'objet d'observations limitées à quelques représentants des familles suivantes: Cyprinodontidés (Harrington, 1975), Platycephalidés (Fujii, 1971) et surtout Serranidés (Bruslé, 1982) et Sparidés (D'Ancona, 1956 ; Lissia-Frau et Casu, 1968, MaloMichele, 1977 ; Lepori, 1980). L'originalité de l'ovotestis réside dans son caractère ambisexuel et dans la mise en place, simultanée ou successive, des deux territoires hétérosexuels, ovarien et testiculaire. Cette dualité morphologique est précoce : chez Lithognathus (Lissia-Frau et Casu, 1968 ; Lepori, 1980), elle se manifeste déjà dans la lame gonadique ayant valeur de crête génitale et se traduit par l'organisation simultanée d'une partie ovarienne dorsale et d'une partie testiculaire ventrale. L'antériorité du développement de la zone ovarienne par rapport à l'aire testiculaire a été soulignée chez Rivulus (Harrington, 1975) et chez Serranus (Bruslé, 1982, 1983). Les observations réalisées dans ces deux genres révèlent la prépondérance ovarienne et l'existence d'une dualité tissulaire précoce, antérieure à la colonisation germinale (Bruslé, 1983). 


\section{II. - Modalités de la différenciation gonadique.}

\section{A) Les types de différenciation.}

D'Ancona (1956) et Yamamoto (1969) distinguent deux catégories de différenciation sexuelle :

1) La différenciation sexuelle directe qui se traduit, à un moment déterminé de l'ontogenèse sexuelle, par l'apparition, dans les gonades indifférenciées, de cellules sexuelles, femelles chez les uns, mâles chez les autres.

2) La différenciation sexuelle indirecte qui consiste d'abord en une différenciation de type femelle dans l'ensemble des individus d'une population, puis, en une évolution ultérieure vers le sexe mâle (différenciation testiculaire secondaire) chez $50 \%$ de ceux-ci.

Au type direct se rattachent la plupart des espèces de Poissons gonochoriques. Au type indirect sont reliés tous les cas d'intersexualité transitoire ou d'hermaphrodisme juvénile, connus notamment chez I'Anguille (Grassi, 1919 ; Kuhlman, 1975; Colombo et Rossi, 1978; mis en doute par Bieniarz et al., 1981), chez Brachydanio (Takahashi, 1977), la Gambusie (Lepori, 1950), le Guppy (Goodrich et al., 1934 ; Dildine, 1936 mais dénié par Mozzi, 1954), chez Micropterus (Johnston, 1951), Lampetra (Busson-Mabillot, 1965; Hardisty, 1965) et Entosphenus (Okkelberg, 1921). Chez la truite arc-en-ciel, l'hypothèse d'une différenciation indirecte (phase femelle initiale puis différenciation testiculaire ultérieure) a été avancée par Mrsic (1923 et 1930) mais niée par Padoa (1939). Les travaux de Lebrun (1977) vont plutôt dans le sens d'une différenciation directe bien que le problème ne soit pas résolu pour une partie des individus étudiés. La présence d'ovocytes intratesticulaires, même à des stades précoces et chez un nombre parfois élevé d'échantillons comme chez le Loup (Roblin et Bruslé, 1983), ne saurait constituer un argument suffisant en faveur d'une différenciation de type indirect.

\section{B) Les aspects anatomiques et cytologiques de la différenciation.}

1) Différenciation anatomique des gonades. - La différenciation morphologique (structurale) des gonades, dans le sens ovarien ou testiculaire, précède généralement la différenciation cytologique, ovogoniale ou spermatogoniale. C'est le cas de Perca (Mezhnin, 1978) et de diverses autres espèces gonochoriques et même hermaphrodites ( $D^{\prime}$ Ancona, 1956). Le nombre, la distribution et le comportement des cellules somatiques constituent les premiers indices de la différenciation, testiculaire ou ovarienne, antérieurement à la différenciation des cellules germinales. Ce critère a été utilisé chez. Oryzias (Yoshikawa et Oguri, 1979) où les cellules interstitielles (étudiées en microscopie électronique par Satoh, 1974, qui leur attribue une valeur de cellules de Leydig) sont décelables, en position périphérique, dès le stade $9 \mathrm{~mm}$, alors que la différenciation germinale est plus tardive (à partir du stade $11,5 \mathrm{~mm}$ ). La sexualisation somatique précède également la sexualisation germinale chez Rivulus (Harrington, 1975) et Cteno- 
pharyngodon (Shelton, 1982). L'importance relative du développement du stroma conjonctif, au cours de l'ontogenèse testiculaire, a été utilisée comme critère de la différenciation sexuelle chez Tilapia (Nakamura et Takahashi, 1973), Rivulus (Harrington, 1975), Brachydanio (Takahashi, 1977), Perca (Mezhnin, 1978) et Gasterosteus (Shimizu et Takahashi, 1980). La complexité de ce stroma où plusieurs types cellulaires ont été identifiés a été montré par Takashima et al., (1980) chez la Truite. Le mésogonium évolue en un mésovarium étroit ou en un mésorchium testiculaire plus large. Ultérieurement, une partie des tissus somatiques de ce secteur s'organise pour ménager une cavité ovarienne dont l'ontogenèse a été décrite chez Carassius (Takahashi et Takano, 1971), Tilapia (Nakamura et Takahashi, 1973), Gasterosteus (Swarup, 1958) et Oncorhynchus (Nakamura et al., 1974) ou bien pour différencier des canaux efférents chez Salmo (Ashby, 1957), Tilapia (Nakamura et Takahashi, 1973) et Poecilia (Takahashi et Iwasaki, 1973). Un développement important des vaisseaux sanguins et des éléments lymphocytaires a été observé dans la gonade à évolution testiculaire, chez la Truite (Padoa, 1939), la Lamproie (Hardisty, 1965) et l'Epinoche (Shimizu et Takahashi, 1980). La mise en place du tissu interstitiel (à activité $3 \beta \mathrm{HSD}+$ ), caractéristique du testicule a été décrite précocement chez Poecilia (Takahashi et Iwasaki, 1973 ; Takahashi, 1975a, b), Salmo (Upadhyay, 1977 ; van den Hurk et al., 1982) et Oryzias (Yoshikawa et Oguri, 1979).

Par ailleurs, la distribution des cellules germinales, de même que la forme et la taille de la gonade peuvent aussi constituer des critères de différenciation sexuelle précoce. Ainsi, la concentration des cellules germinales dans la région corticale de la gonade caractérise la différenciation ovarienne de la Lamproie (Hardisty, 1965), mais traduit l'évolution testiculaire de Xiphophorus (Gordon, 1952 ; Vallowe, 1957). Chez la Truite, un développement important de la région antérieure de la gonade serait le témoignage d'une différenciation ovarienne (Ashby, 1957). De même, chez le Saumon (Robertson, 1953 ; Laird et al., 1978) et chez Oryzias, (Onitake, 1972), l'ovaire présomptif est plus volumineux que le testicule.

2) Différenciation cytologique des gonades. - Chez de nombreuses espèces, le critère de différenciation sexuelle n'est pas seulement architectural mais d'ordre cytologique. En effet, l'activité méiotique précoce et l'accroissement rapide de taille (auxocytose) des ovocytes contrastent d'une part avec le retard d'entrée en méiose et d'autre part avec la plus petite taille des cellules de la lignée mâle.

a) Cellules sexuelles. - La diagnose précoce des gonies et la mise en évidence de leurs caractères distinctifs (spermatogonies, ovogonies) sont seulement possibles au niveau ultrastructural (Bruslé et Bruslé, 1978b ; Bruslé, 1980, 1982). $C^{\prime}$ est pourquoi, le critère de différenciation sexuelle précoce généralement adopté, à l'échelle de la microscopie photonique, est celui de l'entrée en prophase méiotique qui caractérise les ovocytes par opposition à une méiose spermatocytaire beaucoup plus tardive. La reconnaissance d'ovocytes préméiotiques et méiotiques constituerait alors la preuve d'une différenciation en direction ovarienne chez la Lamproie (Hardisty, 1965), la Truite (Vlad, 1976 ; Takashima et al., 
1980), le Saumon (Nakamura et al., 1974 ; Magomedov et al., 1979), Oryzias (Onitake, 1972 ; Satoh, 1974 ; Satoh et Egami, 1972 et 1973 ; Yoshikawa et Oguri, 1981), Hemihaplochromis (Muller, 1969), Poecilia (Takahashi, 1975 a, b), Tilapia (Nakamura et Takahashi, 1973 ; Yoshikawa et Oguri, 1978a, b) et Brachydanio (Takahashi, 1977). Toutefois, ce critère cytologique doit être utilisé avec beaucoup de prudence, d'une part en raison de l'existence de cas de différenciation indirecte (Truite, Anguille, Lamproie...), d'autre part à cause de la présence d'ovocytes intratesticulaires chez les mâles d'espèces à différenciation directe : Tilapia (Avtalion et Mires, 1976 ; Jensen et Shelton, 1979), Cyprinus (Davies et Takashima, 1980), Dicentrarchus (Roblin et Bruslé, 1983). De tels ovocytes (testisova, oocyte-like-cells) parfaitement normaux à l'échelle ultrastructurale (Bruslé, 1982) ne constituent donc nullement une preuve de sexualisation dans un sens femelle.

Une autre preuve de la différenciation sexuelle, dans le sens ovarien, concerne le nombre des cellules germinales, antérieurement à toute différenciation morphologique ou cytologique évidente. Ainsi, chez la Truite (Lebrun, 1977), l'augmentation du nombre des cellules sexuelles est fonction du sexe présumé (1500 chez les femelles présomptives et moins de 1000 chez les mâles présomptifs). Il en est de même chez Xiphophorus (Wolf, 1931) et chez Oryzias (Quirk et Hamilton, 1973). En effet, la multiplication des cellules germinales par activité mitotique caractérise le sexe femelle et contraste avec l'arrêt de prolifération spermatogoniale. Ainsi, les mitoses sont plus actives chez les femelles que chez les mâles, notamment chez Oryzias (Tuzuki et al. 1966 ; Onitake, 1972 ; Satoh, 1974 ; Satoh et Egami, 1972 et 1973 ; Quirk et Hamilton, 1973), mais aussi chez Poecilia (Miyamori, 1964), Channa (Belsare, 1966), Salmo (Ashby, 1957 ; Lebrun, 1977) et Lampetra (Hardisty, 1965). La prolifération spermatogoniale n'intervient que plus tardivement, comme chez Poecilia (Billard, 1973) où peuvent être mises en évidence 14 générations cellulaires successives. Des différences notables, quant au début et à la durée de la phase de multiplication goniale, ont été observées entre espèces voisines chez les Lamproies (Hardisty, 1969 et 1970), les Saumons et les Esturgeons (Persov, 1972) et même entre formes distinctes (anadromes et "landlocked 》) d'une même espèce, comme chez Petromyzon marinus (Hardisty, 1969).

Par ailleurs, un argument complémentaire a été utilisé : l'existence de phénomène d'atrésie. Si les processus constructifs sont les plus importants au cours de la différenciation et de l'édification gonadiques, il est intéressant de noter que ceux-ci sont, dans un certain nombre de cas, accompagnés de processus de dégénérescence de certaines catégories de cellules sexuelles. La destruction précoce de cellules germinales indifférenciées a été décrite chez Oryzias (Gamo, 1961), Polypterus (De Smet, 1970), Scyliorhinus (Thiebold, 1964). De plus, cette atrésie est tardive dans la forme " landlocked 》 de la Lamproie Petromyzon marinus (Hardisty, 1965 et 1969 ; Hardisty et Cosh, 1966) où, après une phase de prolifération des cellules germinales, $70 \%$ d'entre elles environ entrent en dégénérescence lors de la prophase méiotique. L'atrésie ovocytaire est également connue au cours des phases de différenciation ovarienne chez Xiphophorus (Gordon, 1952) et chez Mugil Cephalus (Stenger, 1959). Les processus atrétiques 
sont particulièrement évidents dans les cas d'intersexualité transitoire lou hermaphrodisme juvénile) lorsque l'organisation ovarienne primitive fait naturellement place, dans une partie de la population, à une organogenèse testiculaire. Les ovocytes formés au cours de cette phase femelle initiale persistent un certain temps dans le testicule puis dégénèrent pour disparaître plus ou moins complètement (Brachydanio: Takahashi, 1977; Anguilla: Kuhlman, 1975; Lampetra : Busson-Mabillot, 1965; Hardisty, 1965, 1969 et 1970). La dégénérescence des ovocytes est également observée après intervention expérimentale, consécutivement à des traitements hormonaux (stéroïdes sexuels) au cours de l'inversion sexuelle de nombreuses espèces. Cette atrésie ovocytaire se produit lors de la masculinisation (transformation des ovaires en testicules) de femelles génétiques par des androgènes (11-cétotestostérone et méthyltestotérone chez Tilapia: Nakamura, 1975 ; propionate de testostérone chez Xiphophorus : Vallowe, 1957). Des phénomènes atrésiques sont également observés après utilisation d'œstrogènes (éthynylestradiol agissant dans le sens d'une féminisation des gonades mâles avec dégénérescence des "oocyte-like-cells" de Poecilia : Miyamori, 1964 ; benzoate d'œstradiol provoquant l'atrésie des cellules mâles de Xiphophorus : Mohsen, 1958), de divers stérols (pregnénolone chez Xiphophorus et Poecilia : Mohsen, 1958) ou de corticostéroïdes (DOCA : acétate de désoxycorticostérone : Yamamoto et Matsuda, 1963). La dégénérescence, par pycnose, des cellules mâles est connue seulement chez Scyliorhinus (Collenot, 1969), où la phase juvénile est marquée par une spermatogenèse abortive, mais aussi dans les cas de stérilité induite par des androgènes (Gordon et Aronovitz, 1951, chez Xiphophorus).

b) Les cellules somatiques. - Aucune différence cytologique entre les cellules somatiques annexées aux cellules germinales, dans les deux sexes, n'a pu être mise en évidence, même à l'échelle ultrastructurale (Satoh et Egami, 1973), les cellules Sertoliennes et préfolliculeuses étant homologues et tout à fait comparables à des stades précoces (Bruslé, 1982).

Par contre, les cellules interstitielles constituent un critère de différenciation testiculaire précoce, particulièrement intéressant (Takahashi et Iwasaki, 1973; van den Hurk, 1974 ; Yoshikawa et Oguri, 1979 ; van den Hurk et al., 1982). Les cellules de Leydig du testicule juvénile sont caractérisées par leur début d'activité stéroïdogène décelable par une réaction enzymatique ( $3 \beta$-hydroxystéroïde déshydrogénase $=3 \beta$-HSD). La chronologie de l'établissement des diverses activités enzymatiques ( $3 \beta-H S D, \Delta 5-4$ isomérase, $17 \alpha$-hydroxylase) a été suivie chez la truite par van den Hurk et al., (1982), dans la gonade indifférenciée puis dans l'ovaire et dans le testicule juvéniles. Dans ce dernier, I'activité des $17 \alpha, 20$ desmolases et $11 \beta$-hydroxylase et I'architecture cellulaire (réticulum endoplasmique lisse et mitochondries à crêtes tubulaires) plaident en faveur d'une capacité de synthèse précoce des androgènes par les cellules de Leydig. Par contre, la démonstration de l'existence de stéroïdes testiculaires a été apportée, à des stades plus tardifs, par des tests immunologiques utilisés chez les Salmonidés (Sangalang et al., 1978) pour caractériser les mâles.

L'antériorité de la différenciation somatique par rapport à la différenciation germinale, d'abord niée par Satoh (1974), a été avancée de façon convaincante 
par Yoshikawa et Oguri (1979), et van den Hurk et al., (1982). Le problème des interrelations fonctionnelles entre tissu somatique et tissu germinal, qui met en cause la notion d'inducteur de différenciation, sera discuté ultérieurement.

Ainsi, la recherche des preuves anatomiques et cytologiques de la différenciation sexuelle constitue un problème important auquel diverses réponses ont été proposées, qui varient à la fois selon les espèces étudiées et selon les critères retenus. II convient toutefois de concevoir, comme le fait Nakamura (1981) à propos de Tilapia, que la différenciation germinale morphologique observable est précédée par une différenciation sexuelle physiologique qui concerne l'activation des gènes et l'exécution d'un programme génique, conforme au sexe génotypique et qui se manifeste, à un moment déterminé et durant une période critique, dans les divers composants, germinaux et somatiques, de la gonade. Cette différenciation physiologique ne peut être mise en évidence que de façon indirecte, par voie expérimentale (Nakamura, 1981).

\section{III. - Variabilité de la différenciation gonadique dans le temps et dans l'espace.}

\section{A) Chronologie.}

La période de différenciation sexuelle se situe selon les espèces à des moments fort variés. Chez certains poissons, la différenciation se manifeste durant la vie prénatale ou dès l'éclosion, chez d'autres elle se produit au cours de la vie larvaire précoce ou bien fait suite à un état indifférencié ou transitoirement femelle (hermaphrodisme juvénile) qui peut durer plusieurs mois ou plusieurs années.

Si l'on se réfère à une échelle de temps absolu, peuvent être considérés des cas très divers (tabl. 3 ) : différenciation très précoce (embryonnaire, prénatale ou larvaire précoce: Poecilia, Oryzias, Gasterosteus; larvaire ou postlarvaire : Brachydanio, Tilapia, Carassius), plus tardive au cours des premiers mois de vie (Carpes, Loups, Muges), enfin lente et tardive (Lamproies, Anguilles).

Cette variabilité spécifique de la chronologie de la différenciation sexuelle s'explique par des rythmes de développement bien différents et par des degrés de maturation physiologique variables, d'un individu à l'autre, d'une cohorte à l'autre, d'une espèce à l'autre, d'un sexe à l'autre.

Des variations individuelles ont été signalées chez Oryzias (Gamo, 1961), Salmo (Lebrun, 1977), Tilapia (Jensen et Shelton, 1979), Cyprinus (Davies et Takashima, 1980) et Dicentrarchus (Roblin et Bruslé, 1983). Dans ce dernier cas, des observations effectuées sur des individus issus d'écloseries et maintenus en élevage ont montré une variabilité qui met en cause les bases génétiques.

Les différenciations ovarienne et testiculaire peuvent être synchrones chez certaines espèces (Loup : Roblin et Bruslé, 1983) mais généralement la différenciation femelle se révèle plus précoce que la différenciation mâle : Salmonidés (Ashby, 1957 ; Magomedov et al., 1979 ; Takashima et al., 1980), Tilapia (Nakamura et Takahashi, 1973), Anguilles (Brylirıska et al., 1978), Gasterosteus (Shi- 
TABLEAU 3 Chronologie de la différenciation testiculaire et ovarienne en temps absolu

\begin{tabular}{llll}
\hline Espèces & Taille & Age & Auteurs \\
\hline
\end{tabular}

A) Différenciation sexuelle précoce

1) Période embryonnaire prénatale ou larvaire précoce

\begin{tabular}{|c|c|c|c|}
\hline $\begin{array}{l}\text { Poecilia } \\
\text { reticulata } \\
\text { (ovovipare) }\end{array}$ & $\begin{array}{l}\text { embryon } 5,8 \mathrm{~mm} \\
\text { (o et } q) \\
\text { embryon } 5 \mathrm{~mm} \\
(q) \\
\text { embryon } 8,3 \mathrm{~mm} \\
\left(0^{\circ}\right) \\
\text { embryon }\end{array}$ & $\begin{array}{l}\text { période prénatale } \\
\text { à naissance } \\
7 \mathrm{j} \text { avant naissance } \\
\left\{\begin{array}{lr}Q: 12 \mathrm{j} \text { avant naissance } \\
\mathrm{O}^{*}: 8 \mathrm{j} \text { avant naissance }\end{array}\right.\end{array}$ & $\begin{array}{l}\text { Miyamori, } 1964 \\
\text { Billard, } 1973 \\
\text { Takahashi et } \\
\text { Iwasaki, 1973 } \\
\text { Takahashi, 1975a } \\
\text { Swarup, 1958 }\end{array}$ \\
\hline $\begin{array}{l}\text { Gasterosteus } \\
\text { aculeatus }\end{array}$ & $\begin{array}{l}\text { embryons } \\
\left\{\begin{array}{lr}9 & 9 \mathrm{~mm} \\
0 & 14 \mathrm{~mm}\end{array}\right.\end{array}$ & $\left\{\begin{array}{l}q \\
O^{*}: 10 \mathrm{j} \text { après écl. } \\
: 12 \text { à } 25 \mathrm{j} \text { après écl. }\end{array}\right.$ & $\begin{array}{l}\text { Shimizu et } \\
\text { Takahashi, } 1980\end{array}$ \\
\hline $\begin{array}{l}\text { Scyliorhinus } \\
\text { canicula }\end{array}$ & $\begin{array}{l}\text { embryon } 30-32 \mathrm{~mm} \\
\left(\sigma^{\prime} \text { et } \propto\right) \\
\text { embryon } 29-30 \mathrm{~mm} \\
\left(\sigma^{\prime} \text { et } \propto\right)\end{array}$ & & $\begin{array}{l}\text { Chieffi, } 1955 \\
\text { Thiebold, } 1964\end{array}$ \\
\hline $\begin{array}{l}\text { Oryzias } \\
\text { latipes }\end{array}$ & 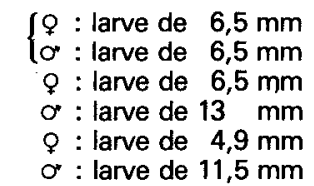 & $\begin{array}{c}2 \mathrm{j} \text { après écl. } \\
24 \mathrm{~h} \text { après écl. } \\
11-15 \mathrm{j} \text { après écl. } \\
2 \mathrm{j} \text { après écl. } \\
2 \mathrm{j} \text { après écl. }\end{array}$ & $\begin{array}{l}\text { Onitake, } 1972 \\
\text { Satoh, 1973, } 1974 \\
\text { Satoh et Egami, } 1972 \\
\text { Yoshikawa et Oguri, } 1979 \\
\text { et } 7981\end{array}$ \\
\hline
\end{tabular}

2) Période larvaire et postlarvaire

\section{Clarias}

batrachus

Brachydanio

rerio

Tilapia

mossambica

larve $15-30 \mathrm{~mm}$

LS

\section{Tilapia}

zillii

Hemihaplochromis

multicolor

Carassius

auratus

Oncorhynchus

keta

Salmo solar

\section{Salmo}

gairdneri
Q larve $8 \mathrm{~mm}$

o larve $18 \mathrm{~mm}$

: larve $11-12 \mathrm{~mm} \mathrm{LT}$

: Larve $11-12 \mathrm{~mm}$

alevins

alevins $26 \mathrm{~mm}$

( $\alpha$ et of)

alevins de 31 à $49 \mathrm{~mm}$

९: 2 à $2,4 \mathrm{~cm} \mathrm{LT}$

ơ : 4,4 à $5,7 \mathrm{~cm} \mathrm{LT}$

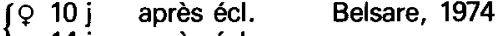

Lo $14 \mathrm{j}$ après écl.

\{ $10-12$ j après écl. Takahashi, 1977

Ơ 23-25 $\mathrm{j}$ après écl. $35-43 \mathrm{j}$

(O' et o $)$

(95-48 j après féc. Hackmann, 1974

$(0)$ et 81 après écl.

$15 \mathrm{j}$

$30 \mathrm{j}$

14 à 25

(on et o)

$40 \mathrm{j}$ après écl.

25-30 j après écl.

$55 \mathrm{j}\left(\mathrm{O}^{*}\right.$ et $Q$ )

o $15 \mathrm{j}$ après écl.

Ơ $58 \mathrm{j}$ après écl.

$60 \mathrm{j}$ après écl. Laird et al., 1978

( $\sigma^{\circ}$ et o $)$

$27 \mathrm{j}$ après écl.

(à $17-20^{\circ} \mathrm{C}$ )

o $121 \mathrm{j}$ après féc.

(à $10-14^{\circ} \mathrm{C}$ )

o $6^{\mathrm{e}}$ semaine après écl.

67 j après féc.

$100 \mathrm{j}$ après féc.

Q $45 \mathrm{j}$ après féc.

Ơ $50 \mathrm{j}$ après féc.
Nakamura et Takahashi, 1973

Yoshikawa et Oguri, 1978

Muller, 1969

Kanobdee, 1975

Takahashi et Takano, 1971

Robertson, 1953

Magomedov et al., 1979

Padoa, 1939

Mrsic, 1923

(Ashby, 1957 ; Vlad, 1976 ;

Lebrun, 1977

Takashima et al., 1980

$\{$ van den Hurk et al., 1980

$\{$ van den Hurk et Slof, 1981 
Rivulus marmoratus Serranus hepatus terr. $q$ : alevin $4,5 \mathrm{~mm}$ LS 28 j

terr. $o^{\circ}$ : alevin $13,3 \mathrm{~mm}$ LS 76 j (à $26^{\circ} \mathrm{C}$ )

terr. $\varsubsetneqq: 2,1 \mathrm{~cm} \mathrm{LT}$

terr. $\sigma^{\circ}: 4,5 \mathrm{~cm} \mathrm{LT}$
Harrington, 1975

Bruslé, 1982, 1983

B) Différenciation sexuelle plus tardive

\begin{tabular}{|c|c|c|c|}
\hline $\begin{array}{l}\text { Cyprinus } \\
\text { carpio }\end{array}$ & $\begin{array}{l}\text { @ juvéniles de } 3-4 \mathrm{~cm} \\
\sigma^{*}\end{array}$ & $\begin{array}{l}65^{\mathrm{e}} \mathrm{j} \text { après écl. } \\
65^{\mathrm{e}} \text { au } 152^{\mathrm{e}} \mathrm{j} \text { après écl. }\end{array}$ & $\begin{array}{l}\text { Davies et } \\
\text { Takashima, } 1980\end{array}$ \\
\hline \multirow[t]{2}{*}{$\begin{array}{l}\text { Dicentrarchus } \\
\text { labrax }\end{array}$} & $\begin{array}{r}\text { Q juvéniles de } 86-90 \\
\mathrm{~mm} \text { LS }\end{array}$ & $12-23$ mois après écl. & Roblin, 1980 \\
\hline & $\begin{array}{ll}\text { O’ juvéniles de } & \text { 104-187 } \\
& \text { mm LS }\end{array}$ & $11^{\ominus}$ au $23^{e}$ mois & Roblin et Bruslé, 1983 \\
\hline Mugil cephalus & juvéniles 200-250 LS & $1-2$ ans & Stenger, 1959 \\
\hline Liza aurata & $\left\{\begin{array}{l}q \text { juvéniles } 12-13 \mathrm{~cm} \text { LT } \\
\text { ơ juvéniles } 16-17 \mathrm{~cm} \text { LT }\end{array}\right.$ & $\begin{array}{l}\text { fin } 1^{\text {re }} \text { année } \\
\text { début } 2^{\mathrm{e}} \text { année }\end{array}$ & $\begin{array}{l}\text { Bruslé et Bruslé, 1978a, } \\
\text { Bruslé, } 1982\end{array}$ \\
\hline
\end{tabular}

C) Différenciation sexuelle lente et tardive

\begin{tabular}{|c|c|c|c|}
\hline $\begin{array}{l}\text { Lampetra } \\
\text { fluviatilis }\end{array}$ & $67-79 \mathrm{~mm}$ & 2 ans & Hardisty, 1970 \\
\hline $\begin{array}{l}\text { Petromyzon } \\
\text { marinus } \\
\text { landlocked } \\
\text { anadrome }\end{array}$ & $\begin{array}{l}>70 \mathrm{~mm} \\
>91 \mathrm{~mm}\end{array}$ & $\begin{array}{l}2 \text { ans } \\
3 \text { ans }\end{array}$ & Hardisty, 1969 \\
\hline $\begin{array}{l}\text { Anguilla } \\
\text { anguilla }\end{array}$ & 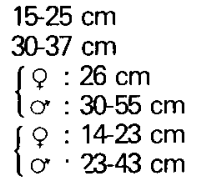 & $\begin{array}{r}4 \text { ans } \\
\\
3-5 \text { ans } \\
1,5-6 \text { ans }\end{array}$ & $\begin{array}{l}\text { Fidora, } 1951 \\
\text { Kuhlman, } 1975 \\
\text { Dolan et Power, } 1976 \\
\text { Colombo et Rossi, } 1978\end{array}$ \\
\hline
\end{tabular}

$\mathrm{j}=$ jour $;$ écl. = éclosion ; féc. = fécondation ; LS = longueur standard ; LT = longueur totale ; terr. = territoire.

mizu et Takahashi, 1980), Cyprinus (Davies et Takashima, 1980), Muges (Bruslé et Bruslé, 1978a). Dans les cas de différenciation d'ovotestis, il est remarquable que le territoire ovarien soit ontogénétiquement plus précoce que le territoire testiculaire (Harrington, 1975 chez Rivulus ; Bruslé, 1983 chez Serranus).

Les facteurs de l'environnement affectent grandement la croissance des poissons et, par voie de conséquence, la vitesse de gonadogenèse. En effet, les différences de sexualisation observées entre poissons des milieux naturels (Kuhlman, 1975, chez l'Anguille; Roblin, 1980, chez le Loup) sont à rapporter non à leur âge absolu mais à l'acquisition d'une certaine taille. L'influence de cette dernière se révèle plus importante que celle de l'âge dans un certain nombre de cas (Kuhlman, 1975 ; Bieniarz et al., 1981 ; Dutta, 1979, cité par Shelton et al., 1981 ; Lebrun, 1977). Cependant, cette opinion a été contredite par plusieurs auteurs (Ashby, 1957 ; Takahashi et Takano, 1971 ; Davies et Takashima, 1980) qui considèrent au contraire que la gonadogenèse dépend de la durée de vie plus que de la taille. 
II convient à ce propos d'insister, comme le fait Vu-Tan-Tue (1976), sur la valeur toute relative de la notion d'âge, inhérente tant aux conditions d'élevage (caractères hydrologiques, température d'incubation et de développement, nourriture...) qu'à celles de l'environnement en milieu naturel (facteurs physicochimiques tels que température et salinité, facteurs trophiques, facteurs sociaux). Le rôle de ces divers facteurs dans le développement sexuel sera analysé dans un chapitre particulier.

II convient de noter enfin que certains auteurs ont insisté sur la durée de la phase indifférenciée et sur sa grande variabilité d'une espèce à l'autre. Réduite au $1 / 24^{e}$ de la période totale de développement des gonades ( 1 mois- 2 ans) chez Oncorhynchus gorbuscha, elle correspond à la moitié de cette période $(9$ ans18 ans) chez Acipenser fluvescens (Persov, 1972). La labilité de ce processus n'implique cependant pas des différences de taux de fécondité et de capacité de reproduction de ces Poissons, bien que la durée du cycle mitotique durant cette phase indifférenciée puisse parfois conditionner le stock germinal et présenter une certaine valeur sélective (Hardisty, 1970).

\section{B) Gradient et asymétrie de différenciation.}

A une variabilité dans le temps de la différenciation sexuelle se superpose une variabilité dans l'espace liée à une distribution hétérogène, céphalocaudale, dorsoventrale ou latérale, des cellules germinales dans les territoires testiculaires et ovariens.

1) Gradient antépostérieur. - La différenciation sexuelle ne se réalise généralement pas à la même vitesse ni avec la même intensité tout au long des gonades. Le plus souvent, elle débute dans la région antérieure et progresse vers l'arrière. Une telle séquence céphalocaudale est connue chez Micropterus (Johnston, 1951), Carassius (Takahashi et Takano, 1971), Poecilia (Takahashi, 1974), Idus (Cala, 1976), Tilapia (Nakamura et Takahashi, 1973 ; Yoshikawa et Oguri, 1978a, b) et Oryzias (Yamamoto, 1953 et 1959 ; Yamamoto et Matsuda, 1963). Chez cette dernière espèce, le gradient n'a pas été confirmé par Yoshikawa et Oguri $(1979,1981)$. Les cellules germinales les plus antérieures se différencient les premières, les plus postérieures demeurant plus longtemps indifférenciées (Yamamoto, 1953 et 1959) et la région postérieure étant parfois privée de gonocytes (Ashby, 1957 ; Takahashi et Takano, 1971). La différenciation somatique, avec organisation d'une cavité ovarienne, progresse également en direction caudale (Nakamura et al., 1974 ; Yoshikawa et Oguri, 1978a, b). Ces derniers auteurs attribuent d'ailleurs à la région antérieure de la gonade un rôle directeur dans la différenciation sexuelle.

Chez d'autres espèces comme Perca, la différenciation débute dans la partie caudale et progresse, en direction crâniale (Mezhnin, 1978). Un net gradient caudocranien, tant de colonisation des crêtes génitales par les CGP que de différenciation ovarienne ou testiculaire, est évident chez le Loup Dicentrarchus (Roblin et Bruslé, 1983). Il permet de reconstituer, sur un même poisson, les séquences des événements cytologiques au cours de la sexualisation et impose, pour juger 
d'un stade de différenciation, d'effectuer des observations à différents niveaux de section des gonades (Roblin, 1980).

De Smet (1975) a montré que la forme générale de la gonade dépend de l'emplacement des gonocytes au cours des premiers stades larvaires. Ainsi, chez les Salmonidés, les gonies sont concentrées dans la région antérieure $(2 / 3$ ant. chez les Truites) et cette partie se renfle pour former un ovaire (Robertson, 1953 ; Ashby, 1957), la région caudale possédant seulement un stroma conjonctif. Chez la Truite arc-en-ciel, Takashima et al., (1980), remarquent, peu après l'éclosion, l'absence de cellules germinales tant dans la région antérieure que dans la région postérieure, tandis que Lebrun (1977) distingue, 5 semaines plus tard, deux types de gonades: les unes où les cellules germinales sont concentrées dans un renflement antérieur et qui évoluent en ovaires, les autres où elles sont réparties sur toute la longueur et qui sont considérées comme des testicules présomptifs. Les CGP sont également groupées dans la région crâniale, qui présente un développement plus important que le reste de la gonade, chez la Carpe (Davies et Takashima, 1980 ; Ryasantseva et Sakun, 1980). Au contraire, chez Micropterus, la partie la plus développée de la gonade se situe dans la zone postérieure (Johnston, 1951).

Par ailleurs, un gradient de sensibilité aux hormones sexuelles a été décelé chez certaines espèces. L'action de l'estradiol est plus importante dans la région postérieure que dans la partie antérieure de la gonade d'Oryzias. Cet effet féminisant aboutit à la formation d'un ovaire postérieur, alors qu'une différenciation testiculaire se manifeste à l'avant (Yamamoto et Matsuda, 1963). De même, chez Xiphophorus, on note une masculinisation des ovaires dans la partie antérieure de la gonade par effet androgène de la prégnénolone (Mohsen, 1958).

2) Gradient dorsoventral. - Une telle hétérogénéité de distribution des tissus gonadiques, déjà sensible chez un certain nombre d'espèces gonochoriques (Lepori, 1980) est de règle en ce qui concerne la plupart des hermaphrodites. L'ontogenèse de l'ovotestis, tant chez les hermaphrodites synchrones (Rivulus : Harrington, 1975 ; Serranus : Bruslé, 1982, 1983) que chez les hermaphrodites successifs (Sparidés tels que la Daurade, Labridés tels que la girelle : Reinboth, 1962, 1970\}, fait apparaître la très nette et très précoce distinction entre territoire ovarien dorsal, et territoire testiculaire ventral. La gonade bisexuelle présente d'abord une différenciation ovarienne non seulement dans les cas de protérogynie (Atz, 1964) mais aussi chez les hermaphrodites synchrones (Harrington, 1975 ; Bruslé, 1983).

3) Dissymétrie et gonades impaires. - Le développement des gonades semble dépendre de la localisation précoce des gonocytes et de leur migration ultérieure au cours des premières étapes larvaires (De Smet, 1975 ; Lebrun, 1977 ; Yoshikawa et Oguri, 1978a, b). Une symétrie de distribution, avec des fréquences de CGP, identiques dans les ébauches gauche et droite, a été mise en évidence chez Channa, (Belsare, 1966), Scyliorhinus (Thiebold, 1964) et Gasterosteus (Swarup, 1958). Par contre, une distribution dissymétrique d'ordre numérique a été notée chez Micropterus (Johnston, 1951), et d'ordre anatomique chez Salmo (Ashby, 1957), Oryzias (Gamo, 1961 ; Yamamoto, 1953), et le Protoptère 
(De Smet, 1975). De plus, chez Oryzias, une dissymétrie d'ordre physiologique a été observée (Yoshikawa et Oguri, 1981), puisque la partie droite de la gonade se différencie (ovocytes) à un stade plus précoce que la partie gauche (gonies indifférenciées). Enfin, une complète asymétrie avec formation d'une gonade unique, impaire, a été mise en évidence chez quelques espèces. Ainsi, l'ovaire gauche de Scyliorhinus se développe au même rythme que le droit jusqu'au stade 35-40 mm, puis il régresse (Chieffi, 1950 et 1959) et s'accole à l'ébauche droite plus volumineuse qui constitue un ovaire droit unique. Une telle atrophie n'est d'ailleurs pas irrévocable et ne résulte pas d'une action inhibitrice de l'ébauche controlatérale, aucune interaction n'ayant été mise en évidence lors des associations de gonades en culture (Thiebold, 1964). Chez Perca, on assiste également à une atrophie de l'ovaire gauche qui fusionne avec l'ovaire droit, seul développé et fonctionnel (Chevey, 1925; Lissia-Frau, 1968 ; Mezhnin, 1978). La gonade d'Atherina dérive de la seule ébauche droite, la crête génitale gauche involuant dans les deux sexes (Arru, 1968). Un ovaire ou un testicule, unique, provenant de la fusion, sur la ligne médiane, de deux ébauches paires symétriques ont été observés chez Xiphophorus (Chavin et Gordon, 1951 ; Gordon, 1952), Gambusia (Chambolle, 1973) et le Guppy (Anteunis, 1959). Enfin, une asymétrie peut résulter d'interventions expérimentales endocrines, comme chez Poecilia où des cas d'inversion sexuelle, chez des femelles génétiques traitées par la 11cétotestostérone, se traduisent par le développement d'un seul testicule, droit ou gauche (Takahashi, 1975a, b).

\section{IV. - Rôles des facteurs de l'environnement et des stéroïdes sexuels}

\section{A) Influence des facteurs de l'environnement.}

La morphogenèse des gonades de Poissons, peut être sous la dépendance de facteurs externes. Parmi ceux-ci, les plus susceptibles d'intervenir dans la cinétique de la différenciation gonadique, citons d'abord la température. La détermination et la différenciation du sexe sont nettement thermolabiles chez Rivulus (Harrington, 1967, 1974 et 1975), puisque des températures élevées $\left(26^{\circ} \mathrm{C}\right)$ sont favorables à un développement d'ovotestis alors qu'à $19^{\circ} \mathrm{C}$ la gonade se différencie dans un sens testiculaire (production de mâles gonochoriques primaires). L'induction d'une différenciation testiculaire par de basses températures est également connue chez Epiplatys (Van Doorn, 1962), alors qu'un accroissement thermique peut induire un développement femelle chez Gasterosteus (Lindsey, 1962, cité par Harrington, 1967). Chez la Truite, les cas d'intersexualité juvénile sont liés à un développement à faible température (Mrsic, 1923 ; Padoa, 1939) et les tendances mâles sont mieux exprimées à haute température (Ashby, 1964). L'influence des facteurs thermiques sur la gonadogenèse a été particulièrement étudiée chez les Salmonidés et les Anguillidés. Ainsi, chez Salmo, la température d'élevage agit sur la vitesse de morphogenèse des gonades (Robertson, 1953 ; Jalabert et al., 1974a) et détermine la durée de différenciation : 121 jours à $10-14{ }^{\circ} \mathrm{C}$ (Mrsic, 1923) et 27 jours à $17-20^{\circ} \mathrm{C}$ (Padoa, 1939). 
Toute augmentation de la température provoque une différenciation sexuelle plus précoce (Lebrun, 1977), qui peut être évaluée en nombre de degrés-jours (temps en jours $x$ température en ${ }^{\circ} \mathrm{C}$ ). La cinétique de différenciation sexuelle a été exprimée en degrés-jours (tabl. 4) chez la Truite (Lebrun, 1977) et chez différentes espèces de saumons (Persov, 1975 ; Goetz et al., 1979; Magomedov et al., 1979).

Chez Anguilla anguilla, la température optimale de développement ovarien est de $26{ }^{\circ} \mathrm{C}$ selon Kuhlman (1975) et la différenciation testiculaire est liée à une augmentation de la température d'après D'Ancona (1957). De même, la sensibilité de la gonade à l'action d'inducteurs sexuels exogènes, tels que le propionate de testostérone, varie en fonction de la température. Ainsi, la phase critique sensible dure du $14^{\mathrm{e}}$ au $16^{\mathrm{e}}$ jour à $26^{\circ} \mathrm{C}$ et du $16^{\mathrm{e}}$ au $18^{\mathrm{e}}$ jour à $23^{\circ} \mathrm{C}$ chez Hemihaplochromis (Hackmann et Reinboth, 1974).

La salinité intervient également dans la différenciation sexuelle de l'Anguille, le pourcentage des femelles étant toujours supérieur dans les eaux intérieures à faible salinité alors que les mâles dominent dans les eaux côtières à salinité élevée (Fidora, 1951). Les facteurs du milieu, associés à ceux de densité de population, sont jugés (Colombo et Rossi, 1978) responsables de la différenciation sexuelle

\section{TABLEAU 4}

Développement gonadique en degrés-jours (temps en jours $\times$ température en ${ }^{\circ} \mathrm{C}$ ) chez les Salmonidés

\begin{tabular}{|c|c|c|c|}
\hline Espèces & Godanogenèse & Degrés-jours & Auteurs \\
\hline Salmo gairdneri & différenciation ovarienne & $772 \mathrm{~d} / \mathrm{j}$ & Lebrun, 1977 \\
\hline Salmo solar & différenciation sexuelle & $1067 \mathrm{~d} / \mathrm{j}$ (61-66 jours) & Parsov, 1975 \\
\hline $\begin{array}{l}\text { Oncorhynchus } \\
\text { kisutch }\end{array}$ & différenciation sexuelle & $\begin{array}{l}880 \mathrm{~d} / \mathrm{j} \text { ( } 49 \text { jours) } \\
\text { après éclosion } \\
834 \mathrm{~d} / \mathrm{j} \text { (50 jours) }\end{array}$ & $\begin{array}{l}\text { Goetz, } 1977 \text { cité Goetz } \\
\text { et al., } 1979 \\
\text { Persov, } 1975\end{array}$ \\
\hline \multirow[t]{3}{*}{ Oncorhynchus keta } & $\begin{array}{l}\text { CGP dans les crêtes géni- } \\
\text { tales }\end{array}$ & $\begin{array}{l}379 \mathrm{~d} / \mathrm{j}\left(10^{\circ} \text { jour }\right. \\
\mathrm{d}^{\prime} \text { incubation) }\end{array}$ & \\
\hline & mitoses goniales & $\begin{array}{l}517,8 \mathrm{~d} / \mathrm{j}\left(25^{\mathrm{e}} \text { jour }\right. \\
\mathrm{d}^{\prime} \text { incubation = éclosion) }\end{array}$ & \\
\hline & premiers ovocytes & $\begin{array}{l}645 \mathrm{~d} / \mathrm{j} \text { (15 jours après } \\
\text { éclosion) }\end{array}$ & \\
\hline \multirow[t]{3}{*}{ femelle } & ovocytes en diplotène & $\begin{array}{l}706 \text { à } 728 \mathrm{~d} / \mathrm{j} \text { (27 à } 33 \text { jours } \\
\text { après éclosion) }\end{array}$ & Magomedov et al., 1979 \\
\hline & prévitellogenèse & $\begin{array}{l}1055 \mathrm{~d} / \mathrm{j} \text { (75 jours après } \\
\text { éclosion) }\end{array}$ & \\
\hline & $\begin{array}{l}\text { synthèses RNA } \\
\text { ovocytaires }\end{array}$ & $\begin{array}{l}1147,3 \mathrm{~d} / \mathrm{j} \text { ( } 55 \text { jours } \\
\text { après éclosion) }\end{array}$ & \\
\hline mâle & spermatogonies & $\begin{array}{l}906,5 \mathrm{~d} / \mathrm{j} \text { (55 jours après } \\
\text { éclosion) }\end{array}$ & \\
\hline Salvelinus fontinalis & différenciation sexuelle & $\begin{array}{l}\text { début : } 750 \mathrm{~d} / \mathrm{j} \\
\text { fin : } 1250 \mathrm{~d} / \mathrm{j}\end{array}$ & $\begin{array}{l}\text { Wenstrom, } 1975 \text { (cité par } \\
\text { Donaldson et Hunter, 1982) }\end{array}$ \\
\hline
\end{tabular}


d'Anguilla. Cependant, aucune étude expérimentale ne permet de dégager de conclusion claire quant au rôle respectif des divers paramètres. Chez le Loup Dicentrarchus (Roblin et Bruslé, 1983), il est apparu que, dans une station d'élevage, à une même température, des différences sensibles de croissance et de développement gonadique étaient corréles à la salinité des eaux (une salinité de 12 à $13 \%$ ó étant plus favorable que des eaux dessalées de 1 à $2 \%$ oo. Hardisty (1965), après avoir nié que les facteurs de l'environnement puissent jouer un rôle significatif sur la différenciation du sexe de Lampetra planeri, admet, chez une autre espèce de Lamproie Petromyzon marinus, une différence de développement gonadique de l'ordre de 1 an entre la forme "landlocked » et la forme anadrome (Hardisty, 1969).

Les paramètres biotiques de l'environnement et en particulier les facteurs trophiques et sociaux interviennent également sur les modalités de la gonadogenèse et sur la labilité de la différenciation sexuelle. Aucune étude n'a porté sur les conditions de l'alimentation et seules quelques comparaisons ont été effectuées entre espèces sauvages des milieux naturels et formes d'élevage (Persov, 1972, sur Vimba ; Mailyan et Alekperov, 1976, sur Acipenser ; Roblin, 1980 sur Dicentrarchus).

L'importance des facteurs sociaux a d'abord été évoquée, en fonction des densités de peuplement, chez l'Anguille (Colombo et Rossi, 1978) où la pression sociale peut (pour des raisons de malnutrition ?) provoquer la différenciation phénotypique mâle des femelles génétiques (Tesch, 1977 ; Passakas et Tesch, 1980). Le contrôle social de l'inversion sexuelle de diverses espèces (tropicales) d'hermaphrodites successifs est maintenant établi (Moyer et Nakazono, 1978 ; Fricke, 1979 ; Bruce, 1980), bien que les interactions sociales soient subtiles et le mode d'action des stimuli exogènes (phéromones ?) encore ignoré (Reinboth, 1980).

Les problèmes posés par cette différenciation " écologique " du sexe (Harrington, 1975) sont difficiles à traiter puisque la gonadogenèse, tout comme la croissance, est la résultante de mécanismes métaboliques complexes, sensibles aux facteurs abiotiques et biotiques de l'environnement. Le mode d'intervention de ces facteurs, soit directement au niveau cellulaire, soit indirectement à divers niveaux métaboliques, est contrôlé par des mécanismes neuroendocriniens régulateurs mettant en jeu I'axe hypothalamo-hypophysaire (Peter, 1981, 1982) avec intervention des stéroïdes sexuels (Billard et al., 1982; Donaldson et Hunter, 1982.

\section{B) Activité des stéroïdes sexuels.}

II a été suggéré par Yamamoto (1962) que les stéroïdes sexuels pouvaient constituer des inducteurs naturels, les hormones androgènes agissant comme inducteurs testiculaires (androinducteurs ou androtermones) et les hormones œstrogènes comme inducteurs ovariens (gynoinducteurs ou gynotermones). Cette hypothèse avait précédemment été rejetée par Witschi (1950) parce que les stéroïdes sexuels provoquent souvent un effet inhibiteur sur le développement des gonades juvéniles alors que les inducteurs naturels sont au contraire caractérisés par leur action stimulante de la gonadogenèse. On considère actuellement 
que les stéroïdes sexuels agissent comme inducteurs artificiels de la différenciation sexuelle (Yamamoto, 1969). Les nombreuses expériences entreprises ont montré que les réponses varient considérablement d'une espèce à l'autre et selon les conditions expérimentales (doses utilisées, stade de développement, moment et durée de leur application). Des différences de sensibilité aux stéroïdes et donc de réponse aux traitements, se manifestent parfois également à l'intérieur d'une même gonade, en fonction d'un gradient antépostérieur (Yoshikawa et Oguri, 1981 chez Oryzias ; Nakamura et Iwahashi, 1982 chez Tilapia). Chez les Téléostéens, des expériences de transplantation (Satoh et Egami, 1973, chez Oryzias) et surtout des traitements hormonaux (Yamamoto, 1962 ; Satoh et Egami, 1973, chez Oryzias; Tayamen et Shelton, 1978 ; Yoshikawa et Oguri, 1978 ; Nakamura, 1981 ; Shelton et al., 1981 ; Nakamura et Iwahashi, 1982 chez Tilapia) ont mis en évidence la possibilité d'une inversion sexuelle des gonades juvéniles.

a) Les hormones androgènes. - Le propionate de testostérone, la méthyltestostérone (MT) et la 11-cétotestostérone inhibent le développement ovarien et I'ovogenèse (Regnier, 1938, chez Xiphophorus; Ashby, 1957, Yamazaki, 1976, Okada et al., 1979, van den Hurk et al., 1980, chez Salmo l. Ces substances provoquent chez Tilapia soit la formation d'une gonade de type neutre (Yoshikawa et Oguri, 1978), soit une masculinisation des femelles (Nakamura, 1975). Ces " mâles expérimentaux » présentent des testicules normaux contenant des ovocytes résiduels en prévitellogenèse, comme chez Tilapia (Tayamen et Shelton, 1978 ; Jensen et Shelton, 1979 ; Nakamura, 1981). Dans de nombreux cas, les androgènes stimulent le développement testiculaire en induisant une activité spermatogénétique (masculinisation) chez les femelles génétiques (Oryzias: Yamamoto, 1953, 1958; Hishida, 1962, 1964; Hishida et Kawamoto, 1970 ; Satoh et Egami, 1973; Tilapia : Clemens et Inslee, 1968 ; Guerrero, 1975 ; Carassius : Yamamoto et Kajishima, 1968 ; Xiphophorus : Vallowe, 1957 ; Poecilia : Dzwillo, 1966 ; Takahashi, 1975a et b). Toutefois, les résultats obtenus expérimentalement varient en fonction du mode d'administration des hormones (voie orale, injection...), des doses utilisées et surtout du moment du début du traitement ainsi que la durée de celui-ci (Jalabert et al., 1974a, b ; van den Hurk et Slof, 1981). Une masculinisation complète des femelles génétiques qui deviennent des mâles fonctionnels a été obtenue chez Salmo gairdneri (Johnstone et al., 1979a, Okada et al., 1979 ; van den Hurk et Slof, 1981).

Certains de ces traitements peuvent produire des intersexués (Takahashi, 1974, chez Poecilia ; Nakamura et Iwahashi, 1982, chez Tilapia), des hermaphrodites simultanés autoféconds (Jalabert et al., 1974 et 1975 chez Salmo) ou encore des individus stériles (Takahashi et Takano, 1971 chez Carassius ; Eckstein et Spira 1965 chez Tilapia ; Goetz et al., 1979, chez Oncorhynchus ; Jalabert et al., 1974 ; Yamazaki, 1976 ; van den Hurk et Slof, 1981 ches Salmo I. A haute dose, les hormones androgènes provoquent un effet paradoxal qui consiste soit en un arrêt du développement testiculaire (Ashby, 1957 chez Salmo), soit en une production d'intersexués chez les mâles génétiques (Muller, 1969 ; Hackmann, 1974 chez Hemihaplochromis ; Hackmann, 1974, chez Cichlasomal, soit enfin en une féminisation de ces mêmes mâles chez Tilapia ; (Nakamura, 1975), chez 
divers Cichlidés (Hackmann, 1974 ; Hackmann et Reinboth, 1974) et chez des Elasmobranches (Chieffi, 1959). Une revue des divers traitements par les androgènes et de leur effet paradoxal possible a été récemment publiée par Donaldson et Hunter, 1982).

b) Les hormones œstrogènes . - Les stéroïdes sexuels tels que l'œestradiol, l'œstrone, le stilbestrol, l'éthynylestradiol sont susceptibles de provoquer une inhibition du développement testiculaire (Eckstein et Spira, 1965, Yoshikawa et Oguri, 1978, chez Tilapia ; Berkowitz, 1941, Miyamori, 1964, chez Poecilia ; Padoa, 1937, 1939 ; Okada, 1973, chez Salmo). Ils provoquent également un début d'inversion sexuelle par induction d'une ovogenèse après dégénérescence des cellules mâles chez Oryzias (Yamamoto et Matsuda, 1963 ; Hishida, 1964 ; Onitake, 1972) et conduisent à la formation d'ovotestis (Berkowitz, 1941, chez Poecilia ; Thiebold, 1964 chez Scyliorhinus) et à l'obtention d'intersexués (Muller, 1969 ; Hackmann et Reinboth, $1974 \mathrm{chez}$ Hemihaplochromis) ou d'hermaphrodites (Jalabert et al., 1974 chez Salmo ; Johnstone et al., 1979b, chez Salvelinus). Les œstrogènes peuvent aussi induire une transformation morphologique complète des gonades dans le sens d'une féminisation des mâles génétiques chez Tilapia (Nakamura et Takahashi, 1973 ; Tayamen et Shelton, 1978 ; Hopkins et al., 1979), Poecilia (Miyamori, 1964), Salvelinus (Johnstone et al., 1979b), Salmo (Johnstone et al., 1979a) Oncorhynchus (Goetz et al., 1979) et Oryzias (Yamamoto, 1953, 1959 et 1962 ; Hishida, 1964). Une telle féminisation peut être, selon le moment et la durée du traitement, incomplète. Elle se traduit alors par la présence d'ovocytes intratesticulaires, plus nombreux et aboutit à la production d'hermaphrodites à maturation synchrone. Enfin, cette féminisation peut être complète et définitive, les ovaires étant identiques à ceux des femelles témoins (Johnstone et al., 1979b chez Salvelinus).

A certaines doses, appliquées précocement, les œstrogènes provoquent une puissante inhibition du développement gonadique et une stérilisation des gonades, surtout des testicules, par élimination des cellules germinales et somatiques (Eckstein et Spira, 1965, chez Tilapia ; Vanyakina, 1968 cité par Yoshikawa et Oguri, 1978 chez Macropodus ; Goetz et al., 1979, chez Oncorhynchus ; Ashby, 1957 ; Jalabet et al., 1974b chez Salmo).

Une revue complète de l'action des œstrogènes a été récemment publiée par Donaldson et Hunter (1982).

Les corticostéroïdes tels que le DOCA (acétate de désoxycorticostérone) produisent un effet inhibiteur sur la gonadogenèse de deux sexes (Ashby, 1957 chez Salmo ; Yamamoto et Matsuda, $1963 \mathrm{chez}$ Oryzias ; Chieffi, $1959 \mathrm{chez}$ les Elasmobranches). De même, la prégnénolone et la progestérone exercent des activités inhibitrices quoique moins puissantes et susceptibles de provoquer une intersexualité, avec développement d'un ovotestis, chez Xiphophorus (Mohsen, 1958) et chez Oryzias (Yamamoto et Matsuda, 1963). L'activité de la progestérone peut se traduire, dans certaines conditions et chez la truite Salmo, par une féminisation des gonades (van den Hurk et al., 1981).

L'activité des stéroïdes apparaît particulièrement subtile en fonction des diverses conditions expérimentales et des seuils de sensibilité cellulaire. Ainsi, chez Oryzias, Yoshigawa et Oguri (1981) distinguent 3 catégories de cellules ger- 
minales (indifférenciées, en différenciation, différenciées) dont les réponses aux stimuli hormonaux sont différentes bien qu'inexpliquées.

Quelles que soient ces incertitudes, il est important de noter que l'utilisation des stéroïdes tend à se généraliser en aquaculture, soit pour la production de populations monosexuées, soit pour l'obtention d'individus stériles à meilleure croissance somatique, soit enfin à titre d'anabolisants (McBride et Fagerlund, 1976 ; Fagerlung et McBride, 1975 ; Yamazaki, 1976 ; Higgs et al., 1977 ; Lam, 1982 ; McBride et al., 1982). Ces deux premières applications seront considérées dans le prochain chapitre.

\section{V. - Intérêt pratique : contrôle du sexe appliqué à l'élevage des poissons}

Diverses interventions expérimentales destinées à réduire certains inconvénients tels que retards de croissance ou mortalités liés à l'un des sexes et à profiter d'une meilleure conversion alimentaire ou de meilleurs indices de carcasse, sont devenues classiques en pisciculture (Chevassus et al., 1979a). Elles s'appliquent en particulier aux Salmonidés (Donaldson et Hunter, 1982) et consistent principalement, les unes à modifier le sexe des Poissons (inversion sexuelle visant à la production de populations monosexes), les autres à inhiber plus ou moins complètement le développement gonadique (obtention d'individus stériles).

\section{A) Populations monosexuées.}

La production en élevage de populations unisexuées ou monosexes offre l'avantage d'éviter les manipulations de sexage des poissons et de permettre les meilleurs taux de croissance du sexe choisi. Les principales techniques de contrôle du sexe utilisées (Schreck, 1974 ; Simpson, 1976 ; Chevassus et al., 1979b ; Donaldson et Hunter, 1982 ; Lam, 1982) sont la gynogenèse, I'hybridation et surtout les traitements hormonaux (androgènes ou œstrogènes), ceux-ci pouvant être directs ou indirects (Goetz et al., 1979).

Le contrôle du sexe par inversion sexuelle dérive des recherches de Yamamoto et Kajishima (1968) qui ont montré, chez Carassius, la possibilité d'orienter le sexe des alevins indifférenciés dans un sens mâle ou femelle grâce à un apport exogène, de stéroïdes sexuels dans l'alimentation. Par ailleurs, les travaux de Yamamoto (1969), chez Oryzias, ont abouti à l'obtention d'individus uniquement femelles, issus du croisement, avec des femelles normales $(X X)$, de femelles homogamétiques $(X X)$ inversées en mâles fonctionnels après traitement par des hormones androgènes. Ce dernier procédé est particulièrement avantageux par rapport aux méthodes d'inversions sexuelles directes puisque les stéroïdes ne sont pas administrés aux poissons destinés à la consommation, mais seulement au stock de géniteurs. II a surtout été utilisé chez Tilapia mossambica (Clemens et Inslee, 1968) et $T$. nilotica (Jalabert et al., 1974b) dans le sens de production de femelles, et chez T. aurea (Guerrero, 1975 ; Shelton et al., 1981), T. hornorum (Chen, 1969), T. nilotica (Tayamen et Shelton, 1978), T. macrochir (Jalabert et al., 1971) afin d'obtenir au contraire des descendances mâles à croissance 
rapide. II convient d'ailleurs de remarquer qu'un même traitement (méthyltestostérone), appliqué au même moment, pendant une même durée et avec une même dose chez deux espèces voisines (Jalabert et al., 1974b), provoque des réponses très différentes : induction complète et fonctionnelle du sexe mâle pour tous les poissons traités chez Tilapia nilotica et disparition complète de la lignée germinale, donc stérilité, chez Tilapia macrochir.

Un autre procédé de contrôle du sexe est la gynogenèse qui, dans le cas d'espèces à femelle homogamétique, permet d'obtenir des descendances purement femelles. La technique consiste à irradier le sperme (en particulier par les radiations $\gamma$ émises par le cobalt 60 ) puis à restaurer la diploïdie par choc thermique (Chourrout, $1980 \mathrm{chez}$ Salmo). Son application concerne les Poissons plats (Purdom, 1969), les diverses espèces de carpes (Cherfas, 1975 cité par Stanley, 1981 ; Stanley, 1976 ; Nagy et al., 1978 ; Stanley, 1981) et le saumon Oncorhynchus (Refstie et al., 1982). Une gynogenèse peut être également produite par hybridation (Purdom, 1969 ; Burlafok et al., 1973 et Makeeva, 1976, tous deux cités par Stanley, 1981).

Des techniques d'hybridation ont été appliquées aux diverses espèces de Tilapia (Jalabert et al., 1971 ; Pruginin et al., 1975) et permettent (o nilotica $\times$ O macrochir et $\$$ nilotica $\times$ o aurea) la production de $100 \%$ de mâles.

Les procédés de production de populations monosexuées sont actuellement appliqués avec succès à l'échelle commerciale dans les élevages de Tilapias (Mires, 1977 ; Anderson et Smitherman, 1978 ; Shelton et al., 1978), de Truites (Jalabert et al., 1975 ; Simpson, 1976 ; Yamazaki, 1976 ; Johnstone et al., 1979a et b ; Okada et al., 1979), de Saumons (Goetz et al., 1979) et de Carpes (Stanley, 1976 ; Nagy et al., 1978).

\section{B) Populations stériles.}

Diverses méthodes sont applicables en vue de réduire le développement des gonades et de produire des individus stériles (Donaldson et Hunter, 1982).

- L'hybridation interspécifique se pratique chez les Salmonidés (Chevassus, 1979 ; Chevassus et al., 1979a) et chez les Poissons plats (Purdom, 1972 ; Lincoln, 1981a,b).

- L'irradiation précoce des gonades provoque la destruction des cellules sexuelles (Purdom et Woodhead, 1973). Cette technique (cobalt 60) a été appliquée aux Saumons (Bonham et Donaldson, 1972 ; Laird et al., 1981).

- L'obtention d'individus trip/oïdes (Purdom, 1972 chez la Plie) et surtout polyploïdes (Lincoln et al., 1974 ; Allen et Stanley, 1979 chez le Saumon ; Allen et Stanley 1978 chez Salvelinus) par divers procédés (chocs thermiques, antibiotiques, hybridations) s'accompagne d'une extrême réduction des gonades.

De même, certains traitements chimiques comme une injection de méthallibure qui agit à la manière d'une hypophysectomie chimique (Lanzing, 1978) inhibe le développement gonadique tout comme le fait la technique d'autoimmunisation : destruction du testicule de Saumon (Laird et al., 1978 et 1981) et de truite (Secombes et al., 1982) par réaction autoimmune (anticorps antigonade).

- La méthode la plus courante consiste en des traitements hormonaux par des stéroïdes sexue/s qui, incorporés à l'alimentation, présentent un effet anabo- 
lisant important et provoquent une accélération de croissance landrogènes utilisés chez la Truite: Hirose et Hibiya, 1968b; Simpson, 1975-76; Yamazaki, 1976; Matty et Cheema, 1978 ; le Poisson rouge : Hirose et Hibiya, 1968a ; Yamazaki, 1976 et le Saumon : McBride et Fagerlund, 1976 ; Fagerlund et Dye, 1979 ; Yu et al., 1979 - œstrogènes employés chez la Plie : Cowey et al., 1973; la Truite : Simpson, 1976, et le Saumon : Yu et al., 1979). Ces stéroïdes provoquent généralement une inhibition de la gonadogenèse, surtout lorsqu'ils sont appliqués précocement, avant ou pendant la différenciation sexuelle. Ainsi, un traitement du frai de Saumon par la méthyltestostérone $17 \alpha \quad(1 \mathrm{ppm}-$ 72 semaines : Higgs et al., $1977 ; 10$ ppm 72 semaines : Fagerlund et McBride, $1975 ; 2,5$ ppm - 14 semaines ; Yu et al., 1979) aboutit à une stérilité testiculaire. Dans ce cas, les ovaires ne sont pas affectés (Fagerlund et McBride, 1975 ; Yu et al., 1979) ou le sont dans une moindre proportion, avec production d'hermaphrodites et seulement de quelques poissons stériles (Jalabert et al., 1975).

L'utilisation du développement gonadique se traduit par la formation de gonades à cellules germinales en nombre réduit (Takahashi et Takano, 1971 ; Okada et al., 1979 ; Yu et al., 1979), ou de gonades complètement stériles (Yoshikawa et Oguri, 1978a, b ; Laird et al., 1978 ; Jalabert et al., 1974b ; Fagerlund et McBride, 1975 ; Goetz et al., 1979 ; Yu et al., 1979), ou encore par l'absence de toute ébauche génitale unilatérale (Takahashi, 1975b). Des androgènes (méthyltestostérone) ont surtout été utilisés chez les Salmonidés (Yamazaki, 1976 ; Simpson, 1976 ; Johnstone et al., 1979a,b ; van den Hurk et al., 1980 ; van den Hurk et Slof, 1981 ; Donaldson et Hunter, 1982). Des œstrogènes, en particulier l'éthinylestradiol et l'estradiol 17 $\beta$, appliqués à titre expérimental sur Tilapia zillii (Yoshikawa et Oguri, 1978b), Tilapia aurea (Eckstein et Spira, 1965), le Carassin (Takahashi et Takano, 1972), la Truite (Ashby, 1957 ; Jalabert et al., 1975 ; Simpson, 1976 ; Johnstone et al., 1979a) et le Saumon (Goetz et al., 1979) provoquent généralement un arrêt du développement testiculaire, sans modification de la différenciation ovarienne et ne donnent pas lieu à application en pisciculture.

\section{Discussion générale et conclusion.}

La morphogenèse gonadique constitue une étape très importante du développement de tout organisme. Elle pose d'abord un problème fondamental de différenciation cellulaire du soma et du germen. Puis, elle conditionne les étapes ultérieures de la gamétogenèse et de la reproduction. Ses conséquences sont donc directement ressenties au niveau des peuplements naturels et la maîtrise de ce processus se révèle essentielle dans le domaine appliqué (élevages).

L'étude de la gonadogenèse permet d'aborder diverses grandes questions de la biologie touchant l'embryologie, la cytogénétique, la cytodifférenciation germinale, la cytophysiologie, l'immunologie, la biochimie des stéroïdes et l'endocrinologie.

Les recherches entreprises dans les divers groupes zoologiques ont montré une certaine unité des processus morphogénétiques propres aux Vertébrés. 
Cependant, les observations ont révélé une variabilité des modalités de mise en place de la lignée germinale et une complexité des mécanismes de différenciation sexuelle (relations entre le sexe génétique, le sexe gonadique et le sexe corporel : Jost, 1975), qui traduisent de multiples adaptations et diverses relations phylogénétiques.

De nombreuses questions restent encore posées, tant chez les Poissons que chez les autres Vertébrés, en ce qui concerne les " facteurs » de sexualisation. En effet, celle-ci s'effectuerait selon deux modalités d'expression, masculinisation ou féminisation, à partir d'une bipotentialité primitive de l'organisme au cours des périodes embryonnaire, postnatale, larvaire ou juvénile. Les principaux problèmes portant sur la sexualisation des Poissons ont été discutés par Yamamoto (1969), Chan (1970), Harrington (1974, 1975) Lepori (1980), et surtout Reinboth (1970, 1980, 1982). Ils se situent à trois niveaux: les inducteurs hormonaux, l'antigène $\mathrm{H}-\mathrm{Y}$ et les interrelations cellulaires.

Des mécanismes biochimiques ont été mis en cause (théorie des inducteurs: Witschi, 1957, 1965 ; et théorie hormonale: Yamamoto, 1969). Deux hypothèses ont été proposées (Hackmann, 1974 ; Hackmann et Reinboth, 1974) quant à l'activité des inducteurs sexuels :

a) I'hormone femelle (œestrogène) serait responsable d'une féminisation " active » et induirait un phénotype ovarien ; en son absence se manifeste une masculinisation par autodifférenciation testiculaire ;

b) I'hormone androgène provoquerait une masculinisation " active ", son absence se traduisant par une autodifférenciation ovarienne. Cette hormone "dominante » serait produite par le sexe hétérogamétique (Jost, 1965) : hormone testiculaire chez les Mammifères, hormone féminisante chez les Oiseaux. Le sexe hétérogamétique est plus variable chez les Vertébrés inférieurs (Atz, 1964 ; Ohno, 1979) et une telle démonstration de la théorie hormonale n'a pas encore été apportée chez les Poissons (Hackmann et Reinboth, 1974). Le rôle des stéroïdes sexuels (effet physiologique ou seulement pharmacologique ?) tout comme celui d'une hypothétique substance inductrice reste à préciser (Reinboth, 1982). L'attention se porte actuellement sur la biosynthèse des systèmes enzymatiques impliqués dans la production des stéroïdes sexuels naturels (van den Hurk et al., 1982). Une telle voie peut se révéler prometteuse.

Des apports récents concernent l'expression et le rôle d'antigènes membranaires, notamment de l'antigène d'histocompatibilité $Y$ ou antigène $H-Y$. II est lié au sexe hétérogamétique: mâle $(X Y)$ chez les Mammifères et chez certains Amphibiens (Wachtel, 1977), femelle (ZW), chez les Oiseaux (Shalev et al., 1978), chez des Reptiles (Pieau et al., 1979; Zaborski et al., 1979) et chez d'autres Amphibiens (Dournon et Zaborski, 1979 ; Zaborski, 1979a,b). Récemment sa présence a été décelée chez les Poissons, dans les deux sexes chez des Cyprinidés et Salmonidés (Müller et Wolf, 1979), chez les mâles des Cyprinodontes et des Cichlidés (Müller et Wolf, 1979 ; Pechan et al., 1979), chez les femelles de la Truite (Shalev et al., 1978) et de diverses espèces de Muges (Bruslé, 1982). Cet antigène a été considéré (Wachtel et al., 1975 ; Wachtel, 1977) du moins chez les Mammifères, comme le déterminant testiculaire. II jouerait donc 
un rôle essentiel dans la différenciation de la gonade et son action serait prépondérante dans la différenciation gonadique du sexe hétérogamétique (Wachtel et al., 1975 ; Wachtel, 1977). Sa remarquable stabilité et sa conservation phylogénétique, semblent confirmées (Pechan et Tracey, 1980; Zaborski, 1979c ; Zaborski et al., 1979b) et sa mise en évidence chez les Vertébrés inférieurs suscite de grandes espérances quant à sa qualité de facteur (non stéroïdien) de différenciation (Reinboth, 1982). Toutefois, la présence de cet antigène $\mathrm{H}-\mathrm{Y}$ n'implique pas qu'il soit directement en cause dans l'organogenèse sexuelle de tous les Vertébrés. En effet, sa localisation restreinte aux seules cellules testiculaires de I'ovotestis du Serran (Bruslé, 1982) plaide en faveur de l'idée selon laquelle il constituerait un marqueur de la différenciation gonadique (Zaborski et al., 1980) et serait alors contemporain de ce phénomène plutôt qu'agent inducteur de la sexualisation.

Par ailleurs, le problème de la sexualisation doit aussi être posé au niveau cellulaire comme l'ont suggéré Reinboth (1972), Satoh et Egami (1973) et Harrington (1974). Ce phénomène peut impliquer des mécanismes intracellulaires de la cellule germinale elle-même (Satoh et Egami, 1973) ou des mécanismes faisant intervenir des relations structurales et métaboliques entre les cellules germinales et les cellules somatiques qui leur sont associées (Bruslé, 1982). En effet, la cellule somatique qui enveloppe la CGP est susceptible d'intervenir dans sa sexualisation en créant autour d'elle un microenvironnement particulier.

Toutes ces questions justifient de nouvelles recherches susceptibles de révéler l'originalité des Poissons, et en particulier des Téléostéens, auxquels peuvent ne pas s'appliquer certains concepts établis chez les autres Vertébrés.

Recu en décembre 1980. Accepté en décembre 1982.

\section{Références}

AIDA T., 1921. On the inheritance of color in a freshwater fish Aplochelus latipes, with special reference to the sex-linked inheritance. Genetics, 6, 554-573.

ALLEN S. K., STANLEY J., 1978. Reproductive sterility in polyploid brook Trout Salvelinus fontinalis. Trans. am. Fish. Soc., 107, 473-478.

ALLEN S. K., STANLEY J. G., 1979. Polyploid mosaics induced by cytochalasin B in land locked Atlantic salmon Salmo salar. Trans. am. Fish. Soc., 108, 462-466.

ANDERSON C. E., SMITHERMAN R. O., 1978. Production of normal male and androgen sexreversed Tilapia aurea and Tilapia nilotica feed a commercial catfish diet in ponds, 34-42. In R. O. SMITHERMAN, W. L. SHELTON, J. H. GROVER, Culture of exotic Fishes. Symp. Proc. Fish Culture Section, Am. Fish. Soc., Auburn, Ala.

ANTEUNIS A., 1959. Recherches sur la structure et le développement de l'ovaire et de l'oviducte chez Lebistes reticulatus. Arch. Biol,, 70, 783-809.

ARRU A., 1966. Prime indagini sulla gonadogenessi nei Labridi. Boll. zool., 33, 327-333.

ARRU A., 1968. Formazione delle gonada unica e modalita del differenziamento sessuale in Atherina mochon Cuv. Boll. zool., 35, 421. 
ASHBY K. R., 1957. The effect of steroid hormones on the brown trout (Salmo trutta L.) during the period of gonadal differentiation. J. Emb. exp. Morph., 5, 225-249.

ASHBY K. R., 1959. L'effeto de basse concentrazioni di estradiolo e di testosterone sul differenziamento gonadico di Salmo trutta L. Riv. Biol., 51, 453.

ASHBY K. R., 1964. The effect to steroid hormones on the development of the reproductive system of Salmo trutta L. when administered at the commencement of spermatogenetic activity in the testes. Riv. Biol., 58, 139-169.

ATZ J. W., 1964. Intersexuality in fishes, 145-239. In C. N. ARMSTRONG, A. J. MARSHALL, Intersexuality in vertebrates including man. Acad. Press, London.

AVTALION R. R., MIRES D., 1976. Determination of allogenic and xenogenic markers in the genus Tilapia. III. Electrophoretic identification of pseudo hermaphroditism in Tilapia aurea serum. Aquaculture, 7, 391-394.

BELSARE D. K., 1966. Development of the gonads in Channa punctatus (Osteichthyes: Channidae). J. Morph., 119, 467-476.

BELSARE D. K., 1974. Studies on the development of endocrine glands in fishes. IV. Development of the gonads in Clarias batrachus. Zool. Jb. Anat, 93, 165-174.

BERKOWITZ P., 1941. The effects of estrogenic substances in the fish (Lebistes reticulatus). J. exp. zool., 87, 233-243.

BERTIN L., 1958. Sexualité et fécondation. In Traité de zoologie, XIII : Agnathes et Poissons, fasc. 2, 1584-1652. Ed. GRASSĖ P. P., Masson, Paris.

BIENIARZ K., EPLER P., MALCZEWSKI B., PASSAKAS T., 1981. Development of european eel (Anguilla anguilla L.) gonads in artificial conditions. Aquaculture, 22, 53-66.

BILLARD R., 1973. La spermatogenèse des Poissons Poecilidae. 2. Comparaisons avec celle d'autres espèces. Bull. fr. Pisc., 250, 17-34.

BILLARD R., FOSTIER A., WEIL C., BRETON B., 1982. Endocrine control of spermatogenis in Teleost fish. Can. J. Fish. Aquat. Sci., 39, 65-79.

BODEMER C., 1971. Contemporary embryology. Moscow, Mir. Press.

BONHAM K., DONALDSON L. R., 1972. Sex ratio and retardation of gonadal development in chronically $\gamma$ irradiated chinook salmon smolt. Trans. am. Fish. Soc., 101, 428-434.

BRUCE R. W., 1980. Protogynous hermaphroditism in two marine angelfishes. Copeia, 2, 353-355.

BRUSLÉ S., 1980. Etude ultrastructurale des cellules germinales primordiales et de leur différenciation chez Mugil cephalus L. (Téléostéen, Mugilidé). Bull. Ass. Anat., 64, 207-216.

BRUSLÉ S., 1982. Contribution à la connaissance de la sexualité de Poissons Téléostéens marins gonochoriques (Mugilidés) et hermaphrodites (Serranidés). Th. Doct. Sci. nat., Univ. Perpignan, $360 \mathrm{p}$.

BRUSLÉ S., 1983. Contribution to the sexuality of a hermaphroditic Teleost: Serranus hepatus (Serranidés). J. Fish. Biol., (sous presse).

BRUSLÉ S., BRUSLÉ J., 1978a. Early sex differentiation in Mugil (Liza) auratus. Risso, 1810 (Teleostei, Mugilidae). An ultrastructural study. Ann. Biol. anim. Bioch. Biophys., 18, 871875.

BRUSLÉ S., BRUSLÉ J., 1978b. An ultrastructural study of early germ cells in Mugil (Liza) auratus Risso, 1810 (Teleostei, Mugilidae). Ann. Biol. anim. Bioch. Biophys., 18, 1141-1153.

BRYLINSKA M., DUGOSZ M., BOGDAN E., 1978. State of gonad development in eel (Anguilla anguilla) caught in Polish inland waters. Rocz. Nauk. Roln., H, 98, 81-113.

BUSSON-MABILLOT S., 1965. La différenciation sexuelle chez la Lamproie de Planer (Lampetra planeri). Bull. Soc. Zool. Fr., 90, 27-31.

BYSKOV A. G., 1978. The anatomy and ultrastructure of the rete system in the fetal mouse ovary. Biol. Reprod., 19, 720-735.

CALA P., 1970. The development of the oocytes and seasonal changes in the ovary of the ide Idus idus (L.) in the river Kävlingean South Sweden. Caldaria, 50, 579-594.

CALA P., 1976. Age at maturity, testicular development and seasonal changes in the testes of the Ide Idus idus (L.) (Pisces, Cyprinidae) in the river Kävlingean, South Sweden. Inst. Freshwat. Res., 55, 5-14.

CHAMBOLLE P., 1973. Recherches sur les facteurs physiologiques de la reproduction chez les Poissons " ovovipares ". Analyse expérimentale sur Gambusia sp. Bull. Biol. Fr. Belg., 107, 27-101. 
CHAN S. T. H., 1977. Spontaneous sex reversal in fishes, 91-105. In MONEY J., MUSAPH H., Handboock of sexology. Elsevier Biochem. Press.

CHAN S. T. H., 1970. Natural sex reversal in vertebrates. Phil. Trans. roy. Soc. Lond. B., 259, 59-71.

CHAVIN W., GORDON M., 1951. Sex determination in Platypoecilus maculatus. I. Differentiation of the gonads in members of allmale broods. Zoologica, 36, 135-145.

CHEN F. Y., 1969. Preliminary studies on the sex-determining mechanism of Tilapia mossambica Peters and T. hornorum Trewavas. Int. Ver. Theor. Angew. Limnol. Verh., 17, 719-724.

CHEVASSUS B., 1979. Hybridization in Salmonids; results and perspectives. Aquaculture, 17, 113-128.

CHEVASSUS B., BLANC J. M., CHOURROUT D., 1979a. Le contrôle de la reproduction chez les Poissons. II. Reproduction différée et stérilité. Bull. fr. de Pisc., 274, 32-46.

CHEVASSUS B., CHOURROUT D., JALABERT B., 1979b. Le contrôle de la reproduction chez les Poissons. I. Les populations " monosexes ". Bull. fr. de Pisc., 274, 18-31.

CHEVEY P., 1925. Recherches sur la perche et le bar. Etude embryogénique, systematique et biogéographie des Percidés européens. Th. Doct. Sci. nat., Paris, 272 pp.

CHIEFFI G., 1949. Ricerche sul differenziamento dei sessi negli embrioni di Torpedo ocellata. Publ. Staz. zool. Napoli, 22, 57-78.

CHIEFFI G., 1950. II differenziamento dei sessi nei Selaci. Experientia, 6, 465-467.

CHIEFFI G., 1951. Sulla organogenesi della medulla della gonade in Torpedo ocellata $\mathrm{e}$ in Scyliorhinus canicula. Boll. zool., 18, 183-187.

CHIEFFI G., 1955. Sex differentiation in the Pacific salmon Oncorhynchus keta (Walbaum). Can. J. Zool., 31, 1-72.

CHIEFFI G., 1959. Sex differentiation and experimental sex reversal in Elasmobranch fishes. Arch. Anat. micr. Morph. exp., 48 bis, 21-36.

CHOURROUT D., 1980. Thermal induction of diploid gynogenesis and triploidy in the eggs of the rainbow trout (Salmo gairdneri), Reprod. Nutr. Dévelop., 20, 727-733.

CLEMENS H. P., INSLEE T., 1968. The production of unisexual broods by Tilapia mossambica sex-reversed with methyltestosterone. Trans, am. Fish. Soc., 97, 18-21.

COLLENOT G., 1969. Apparition et évolution de l'activité endocrine du testicule de Scyliorhinus canicula (Elasmobranche). Ann. Embryol. Morph., 2, 461-477.

COLOMBO G., ROSSI R., 1978. Environmental influences on growth and sex ratio in different eels populations (Anguilla anguilla L.) of Adriatic coasts, 313-320. In Mc LUSIKY D. S., BERRY A. J., Physiology and behaviour of marine organisms. Pergamon Press.

COWEY C. B., POPE J. A., ANDRON J. W., BLAIR A., 1973. Studies on the nutrition of marine flat fish. The effect of oral administration of diethylstilbesterol and cyroheptadiene on the growth of Pleuronectes platessa. Mar. Biol., 19, 1-6.

D'ANCONA U., 1924. Sulla determinazione del sesso nell' Anguilla. R. Comit. Talass. et Mem., 111.

D'ANCONA U., 1943. Nuove ricerche sulla determinazione sessuale dell' Anguilla. Arch. Oceanogr. Limnol., 3, 159-269.

D'ANCONA U., 1949a. Osservazioni sull' organizzazione della gonade ermafrodita di alcuni Serranidi. Nova Thallassia, 1, 1-15.

D'ANCONA U., 1949b. II differenziamento della gonade e l'inversione sessuale degli Sparidi. Arch. Oceanogr. Limnol., 6, 97-164.

D'ANCONA U., 1950. Détermination et différenciation du sexe chez les Poissons. Arch. Anat. micr. Morph. exp., 39, 274-294.

D'ANCONA U., 1955. Osservazioni sulle gonadi giovanili di Amia calva. Arch. ital. anat. Embryol., 60, 184-200.

D'ANCONA U., 1956. Morphogenèse et différenciation sexuelle chez les Poissons Téléostéens. Bull, Soc. Zool. Fr., 81, 219-229.

D'ANCONA U., 1957. Nuove richerche sulla determinazione sessuale dell' Anguilla. Archo. Oceanogr. Limnol., 11, 69-111.

DAVIES P. R., TAKASHIMA F., 1980. Sex differentiation in common carp, Cyprinus carpio. J. Tokyo Univ. Fish., 66, 191-199. 
DE SMET W. M. A., 1970. The germ cells of Polypterus (Branchipterygii, Pisces). Acta morphol. neerl.-scand., 8, 133-141.

DE SMET W. M. A., 1975. Considérations sur le développement des gonades et des gonoductes chez les Polyptères (Pisces). Arch. Zool. Patholog., 62, 95-127.

DILDINE G. C., 1936. Studies on Teleostean reproduction. I. Embryonic hermaphroditism in Lebistes reticulatus. J. Morph., 60, 261-277.

DOLAN J. A., POWER G., 1976. Sex ratio of american eels, Anguilla rostrata, from the Matamek River system, Quebec, with remarks on problems in sexual identification. J. Fish. Res. Bd Can., 34, 294-299.

DONALDSON E. M., HUNTER G. A., 1982. Sex control in fish with particular reference to Salmonids. Can. J. Fish. Aquat. Sci., 39, 99-110.

DOURNON C., ZABORSKI P., 1979. H-Y antigen as a measure for the genotype detection of normal or temperature sex-reversed phenotype in Pleurodeles. Arch. Anat. Micr., 68, 221222.

DZWILLO M., 1966. Über den Einfluß von Methyltestosteron auf primare und sekundare Geschlechtsmerkmale wahrend verschiedener Phasen der Embryonalentwicklung von Lebistes reticulatus. Zool. Anz., suppl. 29, 471-476.

ECKSTEIN B., SPIRA M., 1965. Effect of sex-hormones on gonadal differentiation in a Cichlid, Tilapia aurea. Biol. Bull., 129, 482-489.

FAGERLUND U. H. M., DYE H. M., 1979. Depletion of radioactivity from yearling Coho salmon (Oncorhynchus kisutch) after extended ingestion of anabolically effective doses of $17 \alpha$ methyltestosterone 1,2-3 H. Aquaculture, 18, 303-315.

FAGERLUND U. H. M., McBRIDE J. R., 1975. Growth increments and some flesh and gonad characteristics in juvenile coho receiving diets supplemented with $17 \alpha$-methyltestosterone. $J$. Fish. Biol., 7, 305-314.

FELIX W., 1906. Geschlechtsdrüsen der Teleostier. Handb. d. vergl. u. exper. Entw/eh. d. Wirbeltiere, 3.

FIDORA M., 1951. Influenza dei fattori ambientali sull' accrescimento e sul differenziamento sessuale delle anguille. Nova Thalassa, 1, 3-37.

FRICKE H. W. 1979. Mating system, resource defence and sex change in the anemonefish Amphiprion akallopisos. Z. Tierpsychol., 50, 313-326.

FUJII T., 1971. Hermaphroditism and sex reversal in fishes of the Platycephalidae. II. Kumococius detrusus and Inegocia japonica. Jap. J. Ichthyol., 18, 109-117.

FUNK J. D., DONALDSON E. M., DYE H. M., 1973. Induction of precoceous sexual development in female pink salmon (Oncorhynchus gorbuscha). J. Fish Res. Bd. Can., 51, 493-500.

GAMO H., 1961. On the origin of germ cells and formation of gonad primordia in the medaka, Oryzias latipes. Jap. J. Zool., 13, 101-115.

GOETZ F. W., DONALDSON E. M., HUNTER G. A., DYE H. M., 1979. Effects of estradiol $17 \beta$ and $17 \alpha$-methyltestosterone on gonadal differentiation in the Coho salmon, Oncorhynchus kisutch. Aquaculture, 17, 267-278.

GOODRICH H. B., BEE J. E., FLYNN C. M., MERCEER N., 1934. Germ-cells and the differentiation in Lebistes reticulatus. Biol. Bull., 67, 83-96.

GORDON M., 1946. Introgressive hybridization in domesticated fishes. I. The behavior of Platypoecilus maculatus gene in Xiphophorus helleri. Zoologica, 31, 77-88.

GORDON M., 1951. Genetics of Platypoecilus maculatus. V. Heterogametic sex determining mechanism in females of a domesticated stock originally from british Honduras. Zoologica, 36, 127-134.

GORDON M., 1952. Sex-determination in Xiphophorus (Platypoecilus maculatus). III. Differentiation of gonads in platyfish from broods having a sex ratio of three females to one male. Zoologica, 37, 91-100.

GORDON M., ARONOWITZ O., 1951. Sex determination in Platypoecilus maculatus. II. History of a male platyfish that sired all-female broods. Zoologica, 36, 147-153.

GRASSI B., 1919. Nuove ricerche sulla storia naturale dell' Anguilla. Mem. R. Comit. Talassogr. italiano, 67, $141 \mathrm{pp}$. 
GROPP A., OHNO S., 1966. The presence of a common embryonic blastema for ovarian and testicular parenchymal (follicular, interstitial and tubular) cells in cattle, Bos taurus. Z. Zellf., 74, 505-528.

GUERRERO R. D., 1975. Use of androgens for the production of all-male Tilapia aurea. Trans. am. Fish. Soc., 104, 342-348.

HACKMANN E., 1974. Einfluss von Androgenen auf die Geschlechtsdifferenzierung verschiedener Cichliden (Teleostei). Gen. comp. Endocrinol., 24, 44-52.

HACKMANN E., REINBOTH R., 1974. Delimitation of the critical stage of hormone - influenced sex differentiation in Hemihaplochromis multicolor (Hilgendrof) (Cichlidae). Gen. comp. Endocrinol., 22, 42-53.

HAHN H. N., 1927. The history of the germ-cells of Cottus bairdii G. J. Morph. Physiol., 43, 2, 427-498.

HAMAGUCHI S., 1979. The effect of methyltestosterone and cyproterone acetate on the proliferation of germ cells in the male fry of the medaka, Oryzias latipes. J. Fac. Sci. Univ. Tokyo, (IV zool), 14, 265-272.

HARDISTY M. W., 1965. Sex differentiation and gonadogenesis in lampreys. I. The ammocoete gonads of the brook lamprey, Lampetra planeri. II. The ammocoete gonads of the landlocked sea lamprey, Petromyzon marinus. J. Zool., 146, 305-345.

HARDISTY M., 1967. The number of Vertebrate primordial germ cells. Biol. Rev., 42, 265-287.

HARDISTY M., 1969. A comparison of gonadal development in the Ammocoetes of the landlocked and anadromous forms of the Sea Lamprey Petromyzon marinus L. J. Fish. Biol., 2, 153166.

HARDISTY M., 1970. The relationship of gonadal development of the life cycles of the paired species of lamprey, Lampetra fluviatilis (L.) and Lampetra planeri (Bloch). J. Fish. Biol., 2, 173-181.

HARDISTY M. W., 1971. Gonadogenesis, sex differentiation and gametogenesis, 295-359. In HARDISTY M. W., POTTER I. C., The Biology of lampreys, Acad. Press, N. Y.

HARDISTY M., COSH J., 1966. Primordial germ-cells and fecundation. Nature, 210, 5043.

HARRINGTON R. W., 1967. Environmentally controlled induction of primary male gonochorists from eggs of the self-fertilizing hermaphroditic fish, Rivulus marmoratus. Biol. Bull., 132, 174-199.

HARRINGTON R. W., 1974. Sex determination and differentiation in fishes, 4-12. In SCHRECK C. B., Control of sex in fishes. Virginia Polytech. Inst.

HARRINGTON R. W., 1975. Sex determination and differentiation among uniparental homozygotes of the hermaphroditic fish Rivulus marmoratus (Cyprinodontidae, Atheriniforms), 249-282. In REINBOTH R., Intersexuality in the animal kingdom, Springer Verlag, Berlin.

HIGGS D. A., FAGERLUND U. H. M., McBRIDE J. R., DYE H. M., DONALDSON E. M., 1977. Influence of combinations of bovine growth hormone, 17 -methyltestosterone and Lthyroxine on growth of yearling coho salmon (Oncorhynchus kisutch.). Can. J. Zool., 55, 1048-1056.

HIROSE K., HIBIYA T., 1968a. Physiological studies on growth-promoting effect of proteinanabolic steroids on fish. I. Effects on goldfish. Bull. Jap. Soc. Sci. Fish., 34, 466-472.

HIROSE K., HIBIYA T., 1968b. Physiological studies on growth-promoting effect of proteinanabolic steroids on fish. II. Effects of 4-chlorotestosterone acetate on rainbow trout. Bull. Jap. Soc. Sci. Fish., 34, 473-481.

HISHIDA T., 1962. Accumulation of testosterone-4-C $\mathrm{C}^{14}$ propionate in larval gonad of the medaka, Oryzias latipes. Embryologia, 7, 57-67.

HISHIDA T., 1964. Reversal of sex differentiation in genetic males of the medaka Oryzias latipes by injecting estrone-16-C14 and diethylstilbestrol (monoethyl-1-C14) into the egg. Embryologia, 8, 234-246.

HISHIDA T., KAWAMOTO N., 1970. Androgenic and male-inducing effects of 11-ketotestosterone on a teleost, the medaka (Oryzias latipes). J. exp. Zool., 173, 279-284.

HOGAN J. C., 1973. The fate and fine structure of primordial germ-cells in the Teleost Oryzias latipes. J. Biol. cell., 59, 2, 146a.

HOGAN J. C., 1978. An ultrastructural analysis of "cytoplasmic markers" in germ cells of Oryzias latipes. J. ultrastr. Res., 62, 237-250. 
HOPKINS K. D., SHELTON W. L., ENGLE C. R., 1979. Estrogen Sex-reversal of Tilapia aurea. Aquaculture, 18, 263-268.

HOSOKAWA K., 1973. Formation of the ovarian wall in young of the medaka. Jap. J. Ichtyol., 20, $185-188$.

HURK R. van den, 1974. Steroidogenesis in the testis and gonadotropic activity in the pituitary during postnatal development of the black molly (Mollienisia latipinna). Proc. Kon. Ned. Akad. Wetensch., C 77, 193-200.

HURK R. van den, 1975. Morphological and functional aspects of the testis of the black molly (Mollienisia latipinna). (Thes., Univ. Utrecht).

HURK R. van den, LAMBERT J. G. D., 1982. Temperature and steroid effects on gonadal sex differentiation in rainbow trout. Int. Symp. Reprod. Physiol. of Fish, Wageningen.

HURK R. van den, LAMBERT J. G. D., PEUTE J., 1982. Steroidogenesis in the gonads of rainbow trout fry (Salmo gairdneri) before and after the onset of gonadal sex differentiation. Reprod. Nutr. Dévelop., 22, 413-425.

HURK R. van den, SLOF G. A., 1981. A morphological and experimental study of gonadal sex differentiation in the rainbow trout, Salmo gairdneri. Cell Tiss. Res., 218, 487-497.

HURK R. van den, SLOF G. A., SCHURER F., 1979. Gonadal sex differentiation in rainbow trout. Congr. europ. comp. Endocr. Soc., Sorrente.

HURK R. van den, SLOF G. A., SCHURER F. A., 1980. Gonadal sex differentiation in rainbow trout, Salmo gairdneri, with special reference to the effects of steroid hormones and N,Ndimethylformamide. Gen. comp. Endocrinol., 40, 323.

JALABERT B., KAMMACHER P., LESSENT P., 1971. Déterminisme du sexe chez les hybrides entre Tilapia macrochir et Tilapia nilotica. Etude de la sex-ratio dans les recroisements des hybrides de première génération par les espèces parentes. Ann. Biol. anim. Bioch. Biophys., 11, 155-165.

JALABERT B., BILLARD R., CHEVASSUS B., 1974a. Tentative de contrôle expérimental du sexe chez la truite arc-en-ciel : production d'animaux stériles et d'hermaphrodites simultanés auto-fécondables. Coll. Aquacult., Brest 1973, Actes Coll. $n^{\circ} 1$ CNEXO, 161-174.

JALABERT B., MOREAU J., PLANOUETTE P., BILLARD R., 1974b. Déterminisme du sexe chez Tilapia nilotica et Tilapia macrochir : action de la méthyltestostérone dans l'alimentation des alevins sur la différenciation sexuelle : obtention de mâles inversés fonctionnels. Ann. Biol. anim. Bioch. Biophys., 14, 729-739.

JALABERT B., BILLARD R., CHEVASSUS B., 1975. Preliminary experiments on sex control in trout : production of sterile fishes and simultaneous self-fertilizable hermaphrodites. Ann. Biol. anim. Bioch. Biophys., 15, 19-28.

JENSEN G. L., SHELTON W. L., 1979. Effects of estrogens on Tilapia aurea : implications for production of monosex genetic male Tilapia. Aquaculture, 16, 233-242.

JOHNSTON P. M., 1951. The embryonic history of the germ-cells of the large mouth bass, Micropterus salmoides. J. Morph., 88, 471-542.

JOHNSTONE R., SIMPSON T. H., YOUNGSON A. F., WHITEHEAD C., 1979a. Sex reversal in salmonid. II. The progeny of sex-reversed rainbow trout. Aquaculture, 18, 13-19.

JOHNSTONE R., SIMPSON T. H., WALKER A. F., 1979b. Sex reversal in salmonid culture. III. The production and performance of all-female populations of brook trout. Aquaculture, 18, 241-252.

JORDAN D. S., 1963. The genera of fishes and a classification of fishes. Stanford Univ. Press, Stanford, $800 \mathrm{p}$.

JOST A., 1965. Gonadal hormones in the sex differentiation of the mammalian fetus, 611-628. In DE HAAN R. L., URSPRUNG H., Organogenesis, Rinehart and Winston Inc., N.Y.

JOST A., 1975. Physiologie du développement. Annuaire Collège Fr., 75e année, cours 74-75, 233-242.

KALLMAN K. D., 1970. Sex determination and the restriction of pigment patterns in populations of a Poecilid fish, Xiphophorus maculatus from the Belize and Sibun Rivers of British Honduras. Zoologica, 55, 1-16.

KALLMAN K. D., SCHREIBMAN M. P., 1973. A sex linked gene controlling gonadotrop differentiation and its significance in determining the age of sexual maturation and size of the platifish, Xiphophorus maculatus. Gen. comp. Endocrinol., 21, 287-304. 
KANOBDEE D., 1975. Oogenesis in the goldfish (Carassius auratus L.) with particular reference to mitochondriogenesis. Ph. D. Thes., Univ. Southampton, U.K., $255 \mathrm{p}$.

KUHLMAN H., 1975. Der Einflu $\beta$ von Temperatur, Futter, Größe und Herkunft auf die sexuelle Differenzierung von Glasaalen (Anguilla anguilla). Helgol. wiss. Meeresunters., 27, 139-155.

LAIRD L. M., ELLIS A. E., WILSON A. R., HOLLIDAY F. G. T., 1978. The development of the gonadal and immune systems in the Atlantic salmon (Salmo salar L.) and a consideration of the possibility of inducing autoimmune destruction of the testis. Ann. Biol. anim. Bioch. Biophys., 18, 1101-1106.

LAIRD L. M., WILSON P. R., HOLLIDAY F. G. T., 1981. Field trick of a method of induction of autoimmune gonad rejection in Atlantic salmon (Salmo solar L.). Reprod. Nutr. Dévelop., 20, $1781-1788$.

LAM T. J., 1982. Applications of endocrinology to fish culture. Can. J. Fish. Aquat. Sci., 39, 11-137.

LANZING W. J. R., 1978. Effect of methallibure on gonad development and carotenoid content of the fins of Sarotherodon mossambicus (Tilapia mossambica). J. Fish. Biol., 12, 181-185.

LEBRUN C., 1977. Différenciation sexuelle des gonades chez la truite arc-en-ciel (Salmo gairdneri). Th. $3^{\text {e }}$ Cycle, Univ. P. et M. Curie, 41 pp.

LEPORI N., 1941. Differenziamento sessuale della gonadi e intersessualita transitoria in Gambusia holbrooki. Arch. ital. Anat. Embryol., 46, 170-204.

LEPORI N., 1950. Osservazioni sulla "Intersessualita transitoria " nei pesci. Boll. Pesca. Piscicol. /drobiol., 23, 206-222.

LEPORI N. G., 1980. Sex differentiation hermaphrodistism and intersexuality in Vertebrates including man. Ed. Piccin, Padua, 345 pp.

LINCOLN R. F., 1981a. The growth of female diploid and triploid plaice (Pleuronectes platessa) flounder (Platichthys flesus) hybrids over one spawning season. Aquaculture, 25, 259-268.

LINCOLN R. F., 1981b. Sexual maturation in triploid male plaice (Pleuronectes platessa) and plaice $\times$ flounder (Platichthys flesus) hybrids. J. Fish Biol., 19, 415-426.

LINCOLN R. F., AULSTAD D., GRAMMMELTVEDT A., 1974. Attempted triploid induction in atlantic salmon (Salmo salar) using cold shocks. Aquaculture, 4, 287-297.

LISSIA-FRAU A. M., 1968. Primi sul differenziamento sessuale e sulla formazione dell' ovario unico di Perca fluviatilis L. Boll. zool., 35, 431-432.

LISSIA-FRAU A. M., CASU S., 1968. II processo gonadogenetico in alcune specie di Sparidi (Teleostei, Perciformes). Studi Sassaresi, 1, 1-23.

McBRIDE J. R., FAGERLUND U. H. M., 1976. Sex steroids as growth promoters in the cultivation of juvenile coho salmon (Oncorhynchus kisutch), 145-161. In J. W. AVAULT Jr., Proc. 7th annu. World Mariculture Soc., San Diego, Calif.

McBRIDE J. R., HIGGS D. A., FAGERLUND U. H. M., BUCKLEY J. I., 1982. Thyroid and steroid hormones : potential for control of growth and smaltification of Salmonids. Aquaculture, 28, 201-209.

MAGOMEDOV G. M., SHIKHSHABEKOV M. M., TEN B. V., 1979. The development and growth of the sex cells of the autumn chum, Oncorhynchus keta, in the Caspian basin. J. Ichtiol., 19, 167-170.

MAHON E. F., HOAR W. S., 1956. The early development of the chum salmon Oncorhynchus keta. J. Morph., 98, 1-47.

MAILYAN R. A., ALEKPEROV A. P., 1976. An experimental study on the growth and development of Sturgeons (Family Acipenseridae). J. Ichtyol., 16, 343-347.

MAL.O-MICHELE M., 1977. Contribution à l'étude histologique de la gonade, en particulier de l'ovaire, chez la Saupe, Boops salpa (L.) (Téléostéen, Sparidae). Données nouvelles sur son type d'hermaphrodisme. Inv. Pesq., 41, 165-183.

MATTY A. J., CHEEMA I. R., 1978. The effect of some steroid hormones on the growth and protein metabolism of rainbow trout. Aquaculture, 14, 163-178.

MEZHNIN F. I., 1978. Development of the sex cells in the early ontogeny of the common perch, Perca fluviatilis. J. Ichtyol., 18, 71-86.

MIRES D., 1977. Theoretical and practical aspects of the production of all male Tilapia hybrids. Bamidgeh, 29, 94-101.

MITTWOCH U., 1973. Genetics of sex differentiation. Acad. Press, N.Y. 
MIYAMORI H., 1964. Study on the morphogenic process of the estrogen-induced feminization of male reproductive organs of Lebistes reticulatus. J. Biol., 15, 1-22.

MOHSEN T., 1958. Contribution à l'étude de la différenciation sexuelle sur Xiphophorus helleri H. et Lebistes reticulatus R. Th., Strasbourg, $131 \mathrm{pp}$.

MOYER J. T., NAKAZONO A., 1978. Protandrous hermaphroditism in six species of the Anemonefish genus Amphiprion in Japan. Jap. J. Ichthyol., 25, 101-106.

MOZZI C., 1954. Sviluppo della gonade in embrione de Lebistes reticulatus. Boll. Zool., 21, 531-539.

MRSIC W., 1923. Die Spätbefruchtung und deren Einfluss auf Entwicklung und Geschlechtsbildung, Experimentell nachgeprusst an der Regenbogenforelle. Arch. mikr. Anat., 98, 129-209.

MRSIC W., 1930. Uber des auftreten intermediarer Stadien bei der geschlechtsdifferenzierung der Forelle. Wilhelm Roux' Archiv., 123, 301-332.

MULLER R., 1969. Die Einwirkyng von sexualhormonen auf die geschlechtsdifferenzierung von Hemihaplochromis multicolor (Cichlidae). Zool. Jb. Physol., 74, 519-562.

MÜLLER U., WOLF U., 1979. Cross-reactivity of Mammalian anti-H-Y antiserum in Teleostean fish. Differentiation, 14, 185-187.

NAGY A., RAJKI K., HORVATH L., CSANYI V., 1978. Investigation on carp, Cyprinus carpio L. gynogenesis. J. Fish Biol., 13, 215-224.

NAKAMURA M., 1975. Dosage-dependent changes in the effect of oral administration of methyltestosterone on gonadal sex differentiation in Tilapia mossambica. Bull. Fac. Fish. Hokkaido Univ., 26, 99-108.

NAKAMURA M., 1981. Effects of 11-ketotestosterone on gonadal sex differentiation in Tilapia mossambica. Bull. jap. Soc. Sci. Fish., 47, 1323-1327.

NAKAMURA M., IWAHASHI M., 1982. Studies on the pratical masculinisation in Tilapia nilotica by the oral administration of androgen. Bull. jap. Soc. Sci. Fish., 48, 763-769.

NAKAMURA M., TAKAHASHI H., 1973. Gonadal sex differentiation in Tilapia mossambica, with special regard to the time of ostrogen treatment effective in inducing complete feminization of genetic males. Bull. Fac. Fish. Hokkaido Univ., 24, 1-13.

NAKAMURA M., TAKAHASHI H., HIROI O., 1974. Sex differentiation of the gonad in the Masu salmon Oncorhynchus masou. Sci. Rep. Hokkaido salmon Hatchery, 28, 1-8.

NATALI V. F., NATALI A. I., 1947. The development and differentiation of the gonads in Cyprinids, in connection with the problem of sex changes. In Training Man. V. I. Lenin Pedag. Inst., 60 , Zool. Dept.

NEDELEA M., STEOPOE I., 1970. Origine, caractères cytologiques et comportement des gonocytes primaires perıdant l'embryogenèse et chez les jeunes larves de Cyprinus carpio (Téléostéens). Anat. Anz., 127, 338-346.

ODUM E. P., 1936. Notes on the history of the germ cells in the toadfish (Opsanus tau). J. Elisha Mitchell Sci. Soc., 52, 235-246.

OHNO S., 1979. Major sex-determining genes. Monographs on Endocrinology Springer Verlag. Berlin, Heidelberg, New York, vol. 11, 140 pp.

OKADA H., 1973. Studies on sex differentiation of Salmonidae. I. Effects of estrone on sex differentiation of the rainbow trout (Salmo gairdneri irideus Gibbons). Sci. Rep. Hokkaido Fish Hatch., 28, 11-21.

OKADA H., MATUMOTO H., YAMASAKI F., 1979. Functional masculinization of genetic females in rainbow trout. Bull. jap. Soc. Fish., 45, 413-419.

OKKELBERG P. O., 1921. The early history of the germ cells in the brook larmpry, Entospherus wilderi (G.), up to and including the period of sex differentiation. J. Morphol., 25, 1-127.

ONITAKE K., 1972. Morphological studies of normal sex-differentiation and induced sex reversal process of gonads in the Medaka, Oryzias latipes. Annot. zool. jap., 45, 159-169.

PADOA E., 1937. Differenziazione e inversion sessuale (femminizziazione) di avanoti de Trotta (Salmo irideus) trattati con ormone folliculare. Mon Zool. ital., 48, 195-203.

PADOA E., 1939. Observations ultérieures sur la différenciation du sexe, normale et modifiée par l'administration d'hormone folliculaire, chez la truite iridée (Salmo irideus). Biomorphosis, 1, 337-354.

PALA M., 1968. Sulla localizzazione delle cellule germinali primordiali nei primi stadi di sviluppo in Gambusia holbrookii (Grd.). Boll. Zool., 35, 435-436. 
PALA M., 1970. The embryonic history of the primordial germ cells in Gambusia holbrookii (Grd). Boll. Zool., 37, 49-62.

PASSAKAS T., TESCH F. W., 1980. Karyological and gonadal sex of eels (Anguilla anguilla) from the german bight and the lower river Elbe. Helgol. Meeresunters., 34, 159-164.

PECHAN P., TRACEY M., 1980. H-Y evolution. Experientia, 36, 356-357.

PECHAN P., WACHTEL S., REINBOTH R., 1979. H-Y antigen in the Teleost. Differentiation, 14, 189-192.

PERSOV G. M., 1972. Functional lability of the reproductive system of fisch. J. Ichtyol., 12, 226-240.

PERSOV G. M., 1975. The period of gonadal differentiation in fishes. In Sex differentiation in fishes, Univ. Leningrad Publ. House, Leningrad, $148 \mathrm{pp}$.

PETER R. E., 1981. Gonadotropin secretion during reproductive cycles in Teleosts : Influence of environmental factors. Gen. comp. Endocr., 45, 294-305.

PETER R. E., 1982. Neuroendocrine control of reproduction in Teleosts. Can. J. Fish. Aquat. Sci., 39, 48-55.

PIEAU C., DORIZZI M., ZABORSKI P., 1979. Expression of $\mathrm{H}-\mathrm{Y}$ antigen in young turtles (Emys orbicularis L.) issued from eggs incubated at different temperatures. Arch. Anat. micr., 68, 3.

PINTO J. S., ANDREU B., 1956. Algunos aspectos del desarrollo inicial del ovario de sardina (Sardina pilchardus Walb). Inv. Pesq., 5, 3-12.

PRUGININ Y., ROTHBARD S., WOHLFARTH G., HALEVY A., MOAV R., HULATA G., 1975. Allmale broods of Tilapia nilotica $\times T$. aurea Hybrids. Aquaculture, 6, 11-21.

PURDOM C. E., 1969. Radiation-induced gynogenesis and androgenesis in fish. Heredity, Lond., 24, 431-444.

PURDOM C. E., 1972. Induced polyploidy in plaice (Pleuronectes platessa) and its hybrid with the flounder (Platichthys flesus). Heredity, Lond., 29, 11-24.

PURDOM C. E., 1979. Genetics of growth and reproduction in Teleosts. Symp. zool. Soc. Lond., 44, 207-217.

PURDOM C. E., WOODHEAD D. S., 1973. Radiation damage in fish. In SCHRÖDER J. H., Genetics and mutagenesis in fish, Springer Verlag.

QUIRK J. G., HAMILTON J. B., 1973. Fumber of germ cells in known male and female genotype of Vertebrate embryos (Oryzias latipes). Science, 8, 963-964.

REFSTIE T., 1982. Practical application of sex manipulation. Int. Symp. Reprod. Physiol. of Fish. Wageningen.

REFSTIE T., STOSS J., DONALDSON E. M., 1982. Production of all females coho salmon (Oncorhynchus kisutch) by diploid gynogenesis using irradiated sperm and cold shock. Aquaculture, 29, 67-82.

REGNIER M. T., 1938. Contribution à l'étude de la sexualité des Cyprinodontes vivipares (Xiphophorus helleri, Lebistes reticulatus). Bull. Biol. Fr. Belg., 72, 385.

REINBOTH R., 1962. Morphologische und funktionelle Zweigeschlechtlichkeit bei marinen Teleostiern (Serranidae, Sparidae, Centracanthidae, Labridae) Zool. Jb. Physiol., 69, 405-480.

REINBOTH R., 1970. Intersexuality in fishes. Mem. Soc. Endocr., 18, 515-543.

REINBOTH R., 1972. Hormonal coritrol of the Teleost ovary. Am. Zoologist, 12, 307-324.

REINBOTH R., 1975. Intersexuality in the animal kingdom. Springer Verlag, 446 pp.

REINBOTH R., 1980. Can be sex inversion be environmentally induced ? Biol. Reprod, 22, 49-59.

REINBOTH R., 1982. The problem of sexual bipotentiality as exemplified by Teleosts. Reprod. Nutr. Dévelop., 22, 387-403.

ROBERTSON J. G., 1953. Sex differentiation in the Pacific Salmon. Can. J. Zool., 31, 73-79.

ROBLIN C., 1980. Etude comparée de la biologie du développement (gonadogenèse, croissance, nutrition) du Loup Dicentrarchus labrax en milieu naturel et en élevage contrôlé. Th. Doct. $3^{\text {e }}$ Cycle, USTL Montpellier, $272 \mathrm{pp}$.

ROBLIN C., BRUSLE J., 1983. Organogenèse gonadique et différenciation sexuelle du loup Dicentrarchus labrax en conditions d'élevage. Reprod. Nutr. Dévelop., 23, 115-127.

RODOLICO A., 1933. Differenziamento dei sessi ed ovospermatogenesi nell anguilla. Publ. Stat. zool. Napoli, 13, 2, 180-278.

RYAZANTSEVA M. V., SAKUN O. F., 1980. The sex cells and development of the gonads in the early ontogeny of the carp, Cyprinus carpio. J. Ichtiol., 20, 1-37. 
SAKUN O. F., 1959. Sex cells and the function of sex cells in the vimba (Vimba vimba) under normal and disrupted conditions of reproduction. Leningrad, Author's Abstr. Candidat. Thes.

SANGALANG G. B., FREEMAN H. C., FLEMMING R. B., 1978. A simple method for determining the sex of fish by radioimmunoassay using 11-ketotestosterone antiserum. Gen. comp. Endocr., 36, 187-193.

SATOH N., 1973. Sex differentiation of the gonad of fry transplanted into the anterior chamber of the adult eye in the teleost. J. Embryol. exp. Morph., 30, 345-358.

SATOH N., 1974. An ultrastructural study of sex differentiation in the Teleost Oryzias latipes. J. Emb. exp. Morph., 32, 195-215.

SATOH N., EGAMI N., 1972. Sex differentiation of germ cells in the teleost Oryzias latipes during normal embryonic development. J. Embr. exp. Morph., 28, 385-395.

SATOH N., EGAMI N., 1973. Preliminary report on sex differentiation in germ cell of normal and transplanted gonads in the fish Oryzias latipes, 29-32. In SCHRÖDER J. H., Springer Verlag, Genetics and mutagenesis of fish.

SCHRECK C. B., 1974. Control of sex in fishes. Ext. Div. Virg. Polytech. Inst. State Univ. Blacksburg.

SCHWIER H., 1939. Geschlechtsbestimmung und Differenzierung bei Macropodus opercularis, concolor, chinensis, und derer Artbastarden. Z. Ind. Abst. Vererb., 77, 291-335.

SECOMBES C. J., LAIRD L. M., PRIEDE I. G., 1982. Fish sterilisation : The autoimmune approach. Int. Symp. Reprod. Physiol. of Fish., Wageningen.

SHALEV A., BERCZI I., HAMERTON J. L., 1978. Detection and cross-reaction of $H-Y$ antigen by haemagglutination. J. Immunogenetics, 5, 303-312.

SHELTON W. L., 1982. Monosex grass carp production through breeding sex - reversed broodstock. Int. Symp. Reprod. Physiol. of Fish. Wageningen.

SHELTON W. L., HOPKINS K. D., JENSEN G. L., 1978. Hormone-induced monosexing of Tilapia for aquaculture, 10-33. In SMITHERMAN R. O., SHELTON W. L., GROVER J. H., Culture of exotic Fishes. Symp. Proc., Am. Fish. Soc., Auburn, Ala.

SHELTON W. L., RODRIGUEZ-GUERRERO D., LOPEZ-MACIAS J., 1981. Factors affecting androgen sex reversal of Tilapia aurea. Aquaculture, 25, 59-65.

SHIMIZU M., TAKAHASHI., 1980. Process of sex differentiation of the gonad and gonoduct of the three-spined stickleback, Gasterosteus aculeatus L. Bull. Fac. Fish. Hokkaido Univ., 31, 137-148.

SIMPSON T. H., 1975-76. Endocrine aspects of salmonid culture. Proc. roy. Soc. Edinburgh, (B), 万5, 241-252.

SIMPSON T. H., 1976. Endocrine aspects of salmonid culture. Proc. roy. Soc. Edinburgh, B, 75. 241-252.

STANLEY J. G., 1976. A review of methods for obtaining monosex fish and progress report on the productive of monosex white Amure. J. Aquat. Plant. Monog., 14, 68-70.

STANLEY J. G., 1981. Manipulation of developmental events to produce monosex and sterile fish. Rapp. P. V. Réun. Cons. Inst. Explor. Mer, 178, 485-491.

STENGER A. H., 1959. A study of the structure and development of certain reproductive tissues of Mugil cephalus Linnaeus. Zoologica, 44, 53-70.

SWARUP H., 1958. The reproductive cycle and development of the gonads in Gasterosteus aculeatus. Proc. zool. Soc. Bengal, 11, 47-61.

TAKAHASHI H., 1974. Modification of the development of female reproductive organs in the guppy, Poecilia reticulata, following an androgen treatment in their juvenile period. Bull. Fac. Fish. Hokkaido Univ., 25, 174-199.

TAKAHASHI H., 1975a. Process of functional sex reversal of the gonad in the female guppy, Poecilia reticulata, treated with androgen before birth. Develop. Growth Diff., 17, 167-175.

TAKAHASHI H., 1975b. Masculinization of the gonad of juvenile guppy, Poecilia reticulata, induced by 11-ketotestosterone. Bull. Fac. Fish. Hokkaido Univ., 26, 11-12.

TAKAHASHI H., 1977. Juvenile hermaphroditism in the Zebrafish, Brachydanio rerio. Bull. Fac. Fish. Hokkaido Univ., 28, 57-65.

TAKAHASHI H., IWASAKI Y., 1973. The occurence of histochemical activity of $3 \beta$-hydroxysteroid dehydrogenase in the developing testes of Poecilia reticulata. Develop. Growth Diff., 15. 241-253. 
TAKAHASHI H., TAKANO K., 1971. Sex hormone-induced precocious hypertrophy and ciliation of epithelial cells in the ovarian lumen of the goldfish. Annot. zool. jap., 44, 32-42.

TAKANO K., 1965. Origin of the oocytes in the adult guppy, Lebistes reticulatus. Bull. Fac. Fish. Hokkaido Univ., 16, 137-142.

TAKASHIMA F., PATINO R., NOMURA M., 1980. Histological studies on the sex differentiation in rainbow trout. Bull. jap. Soc. Sci. Fish., 46, 1317-1322.

TAYAMEN M. M., SHELTON W. L., 1978. Inducement of sex reversal in Sarotherodon niloticus (Linnaeus). Aquaculture, 14, 349-354.

THIEBOLD J. J., 1964. Contribution à l'étude de l'organogenèse et son déterminisme chez un Poisson Elasmobranche : la petite Roussette Scylliorhinus caniculus. Bull. Biol. Fr. Belg., 98, 253-347.

TESCH F. W., 1977. The eel, biology and management of anguillid eels. Chapman \& Hall eds., London, $434 \mathrm{pp}$.

TRUSOV V. Z., 1971. Maturation of the sevryugal (Acipenser stellatus Pallas) testes during its life in the ocean. J. Ichtyol., 11, 216-223.

TUZUKI E., EGAMI N., HYODO Y., 1966. Multiplication and sex differentiation of germ cells during development in the Medaka Oryzias latipes. Jap. J. Ichtyol., 13, 176-182.

UPADHYAY S. N., 1977. Morphologie des gonades immatures et étude expérimentale de l'induction de la gamétogenèse chez la Truite arc-en-ciel juvénile Salmo gairdneri. Th. Doct. Sci., Univ. Paris VI, 111 pp.

VALLOWE H. H., 1957. Sexual differentiation in the teleost fish Xiphophorus helleri, as modified by experimental treatment. Biol. Bull., 112, 422-429.

VAN DOORN W. A., 1962. Geschiachtsbeinvloeding door temperatur. Het. Aquarium, 32, 208-209.

VIVIEN J., 1964. Origine de la lignée germinale chez les Poissons, 283-308. In WOLFF E., L'origine de la lignée germinale chez les Vertébrés et chez quelques groupes d'Invertébrés, Hermann, Paris.

VLAD M., 1976. Nucleolar DNA in oocytes of Salmo irideus (G.). Cell Tissue Res., 167, 3, 407-424.

VU-TAN-TUE, 1976. Etude du développement du tube digestif des larves du Bar Dicentrarchus labrax. Arch. Zool. exp. Gen., 117, 493-509.

WACHTEL S. S., 1977. H-Y antigen and the genetics of sex determination. A minimum of three genes may be required for the differentiation of the mammalian testis. Science, 198, 797799.

WACHTEL S. S., OHNO S., KOO G. C., BOYSE E. A., 1975. Possible role for H-Y antigen in the primary determination of sex. Nature, 257, 235-236.

WITSCHI E., 1934. Genes and inductors of sex differentiation in Amphibians. Biol. Rev., 9, 460.

WITSCHI E., 1942. Hormonal regulation of development in lower Vertebrates. Cold Spring-Harb Symp. Quant. Biol., 10, 145-151.

WITSCHI E., 1950. Génétique et physiologie de la différenciation du sexe. Arch. Anat. micr. Morph. exp., 39, 215-240.

WITSCHI E., 1957. The inductor theory of sex differentiation. J. Fac. Sci. Hokkaido Univ., 13, 428-437.

WITSCHI E., 1965. Hormones and embryonic induction. Arch. Anat. micr. Morph. exp., 54, 601-611.

WOLF L. E., 1931. The history of the germ-cells in the viviparous Teleost Platypecilus. J. Morph. Physiol., 52, 1, 115-154.

YAMAMOTO T., 1953. Artificially induced sex reversal in genotypic males of the Medaka COryzias latipes). J. exp. Zool, 123, 571-594.

YAMAMOTO T., 1958. Artificial induction of junctional sex reversal in genotypic fermales of the Medaka Oryzias latipes. J. exp. Zool., 137, 227-264.

YAMAMOTO T., 1959. The effects of estrone dosage level upon the percentage of sex reversals in genetic male $(X Y)$ of the Medaka (Oryzias latipes). J. exp. Zool., 141, 133-154.

YAMAMOTO T., 1962. Hormonic factors affecting gonadal sex differentiation in fish. Gen. comp. Endocr., suppl. 1, 341-345.

YAMAMOTO T., 1963. Induction of reversal in sex differentiation of YY zygotes in the Medaka, Oryzias latipes. Genetics, 48, 293-306.

YAMAMOTO T., 1968 . Effect of $17 \alpha$-hydroxyprogesterone and androstenidione upon sex-differentiation in the Medaka, Oryzias latipes. Gen. comp. Endocr., 10, 8-13. 
YAMAMOTO T., 1969. Sex differentiation. In HOAR W. S., RANDALL D. J., Fish physiology., vol. III, 3, 117-175. Acad. Press, N.Y.

YAMAMOTO T., KAJISHIMA T., 1968. Sex hormone induction of sex reversal in the goldfish and evidence for male heterogamety. J. exp. Zool., 168, 215-222.

YAMAMOTO T., MATSUDA N., 1963. Effects of estradiol, stilbestrol and some alkyl-carbonyl androstanes upon differentiation in the Medaka Oryzias latipes. Gen. comp. Endocr., 3, 101110 .

YAMAMOTO T., TAKEUCHI K., TAKAI M., 1968. Male induced action of androsterone and testosterone propionate upon XX zygotes in the Medaka Oryzias latipes. Embryologica, 10, 140-151.

YAMAZAKI F., 1976. Application of hormones in fish culture. J. Fish. Res. Bd Can., 33, 948-958.

YEMEL'YANOVA N. G., 1976. Gonad formation and sex differentiation in the silver carp in the ponds of Uzbekistan. Nauch. dok. vysshey shkoly biol. nauki, 11.

YOSHIKAWA H., OGURI M., 1978a. Effects of steroid hormones on the sex differentiation in a Cichlid fish, Tilapia zillii. Bull. jap. Soc. sci. Fish., 44, 1093-1097.

YOSHIKAWA H., OGURI M., 1978b. Sex differentiation in a Cichlid, Tilapia zillii. Bull. jap. Soc. Sci. Fish., 44, 313-318.

YOSHIKAWA H., OGURI M., 1979. Gonadal sex differentiation in the Medaka, Oryzias latipes, with special regard to the gradient of the differentiation of testes. Bull. jap. Soc. sci. Fish., 45, 9, 1115-1121.

YOSHIKAWA H., OGURI M., 1981. Ovarian differentiation in the Medaka Oryzias latipes, with special reference to the gradient of the differentiation. Bull. jap. Soc. sci. Fish., 47, 43-50.

YU T. C., SINNHUBER R. O., HENDRICKS J. D., 1979. Effect of steroid hormones on the growth of juvenile coho salmon (Oncorhynchus kisutch). Aquaculture, 16, 4, 351-359.

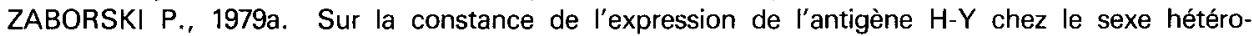
gamétique de quelques Amphibiens et sur la mise en évidence d'un dimorphisme sexuel de l'expression de cet antigène chez l'Amphibien Anoure Pe/odytes punctatus D. C. R. Acad. Sci. Paris, sér. D, 289, 1153-1156.

ZABORSKI P., 1979b. Etude de l'expression de l'antigène H-Y chez les Amphibiens en relation avec I'organogenèse sexuelle. Coll. S.F.B.D., Toulouse, et Arch. Anat. Micr., 68, 3, 221.

ZABORSKI P., 1979c. La conservation phylogénétique de l'antigène $\mathrm{H}-\mathrm{Y}$ et les caractéristiques de son expression chez les vertébrés non mammaliens. $X^{e}$ "Rencontre de Meribel "sur la différenciation cellulaire, 17-23 mars 1979, les Arcs (Savoie).

ZABORSKI P., DORIZZI M., PIEAU C., 1979a. Sur I'utilisation de sérum-H-Y de Souris pour la détermination du sexe génétique chez Emys orbicularis L. (Testudines, Emydidae). $C$. $R$. Acad. Sci. Paris, sér. D, 288, 351-354.

ZABORSKI P., LESOURD S., GONZALES J., 1979b. L'antigène $H-Y$ et le développement de l'appareil génital. La revue de pédiatrie, 15, 523-528.

ZABORSKI P., GUICHARD A., REYSS-BRION M., 1980. H-Y antigen in ovariectomized chicks : disappearance of its expression during the transformation of the right gonad into a testis. Biol. Cell., 39, 291-294.

ZAMBONI L., MAULÉON P., BÉZARD J., 1979. The role of the mesonephros in the development of the fetal sheep ovary. Ann. Biol. anim. Bioch. Biophys., 19, 1153-1178.

ZELENKOV V. M., 1981. Early gametogenesis and sex differentiation in the perch Perca fluviatilis. J. Ichtiol., 21, 124-130. 